\title{
Diffusible signal factor (DSF)-mediated quorum sensing modulates expression of diverse traits in Xanthomonas citri and responses of citrus plants to promote disease
}

\author{
Lei $\mathrm{Li}^{1,2+}$, Jinyun $\mathrm{Li}^{2+}$, Yunzeng Zhang ${ }^{2+}$ and Nian Wang ${ }^{2^{*}}$ (1)
}

\begin{abstract}
Background: The gram-negative Xanthomonas genus contains a large group of economically important plant pathogens, which cause severe diseases on many crops worldwide. The diffusible signal factor (DSF) - mediated quorum sensing (QS) system coordinates expression of virulence factors in plant pathogenic Xanthomonas spp. However, the regulatory effects of this system during the Xanthomonas- plant interactions remain unclear from both the pathogen and host aspects.
\end{abstract}

Results: In this study, we investigated the in planta DSF- mediated QS regulon of X. citri subsp. citri (Xac), the causal agent of citrus canker. We also characterized the transcriptional responses of citrus plants to DSF-mediated Xac infection via comparing the gene expression patterns of citrus trigged by wild type Xac strain 306 with those trigged by its DSF- deficient ( $\triangle r p f F$ ) mutant using the dual RNA-seq approach. Comparative global transcript profiles of Xac strain 306 and the $\triangle$ rpfF mutant during host infection revealed that DSF- mediated QS specifically modulates bacterial adaptation, nutrition uptake and metabolisms, stress tolerance, virulence, and signal transduction to favor host infection. The transcriptional responses of citrus to DSF-mediated Xac infection are characterized by downregulation of photosynthesis genes and plant defense related genes, suggesting photosynthetically inactive reactions and repression of defense responses. Alterations of phytohormone metabolism and signaling pathways were also triggered by DSF-mediated Xac infection to benefit the pathogen.

Conclusions: Collectively, our findings provide new insight into the DSF- mediated QS regulation during plant-pathogen interactions and advance the understanding of traits used by Xanthomonas to promote infection on host plants.

Keywords: Xanthomonas, Diffusible signal factor (DSF), Quorum sensing, Citrus canker, Transcriptomic profiling

\footnotetext{
* Correspondence: nianwang@ufl.edu

${ }^{\dagger}$ Lei Li, Jinyun Li and Yunzeng Zhang contributed equally to this work.

${ }^{2}$ Citrus Research and Education Center, Department of Microbiology and Cell

Science, University of Florida, Lake Alfred, FL 33850, USA

Full list of author information is available at the end of the article
}

(c) The Author(s). 2019 Open Access This article is distributed under the terms of the Creative Commons Attribution 4.0 International License (http://creativecommons.org/licenses/by/4.0/), which permits unrestricted use, distribution, and reproduction in any medium, provided you give appropriate credit to the original author(s) and the source, provide a link to the Creative Commons license, and indicate if changes were made. The Creative Commons Public Domain Dedication waiver (http://creativecommons.org/publicdomain/zero/1.0/) applies to the data made available in this article, unless otherwise stated. 


\section{Background}

The genus Xanthomonas comprises a large group of gram-negative plant pathogenic bacteria that have considerable agricultural impact worldwide, and therefore, is an important model genus for studying the host-pathogen interactions [1, 2]. Successful infection and bacterial multiplication of Xanthomonas spp. in host tissues require coordinated expression of a combination of virulence factors. Key virulence factors of Xanthomonas spp. include, among others, the type III secretion system (T3SS) and its effectors [3, 4], bacterial polysaccharides such as the xanthan extracellular polysaccharides (EPS) and lipopolysaccharides (LPS) [5], and cell wall degrading enzymes [1]. Expression of these virulence factors is regulated by different extracellular stimuli via multiple coordinated regulatory systems, including cell-to-cell communication (quorumsensing, QS) pathways, two-component systems and various transcriptional regulators [1].

The QS regulatory systems of Xanthomonas are mediated by molecules belonging to the diffusible signal factor (DSF) family [2, 6, 7]. The DSF-mediated QS has been studied most extensively in the crucifer pathogen $X$. campestris pv. campestris $(X c c)$. The synthesis and perception of the DSF signal, which was identified as cis-11-methyl-2-dodecenoic acid [8], require the rpf gene cluster (for regulation of pathogenicity factors), including $r p f B, r p f F$ and $r p f G H C[9,10]$. RpfB was initially thought to be involved in DSF biosynthesis, but it was later identified as a fatty Acyl-CoA ligase involved in the turnover of the DSF family of signals in Xanthomonas [11]. The RpfF protein, functioning as a putative enoyl-CoA hydratase, is responsible for the synthesis of DSF. RpfC and RpfG consist of a two-component system involved in DSF perception and signal transduction. RpfC is a hybrid sensor kinase and RpfG is a response regulator with a CheY-like receiver (REC) domain and an HD-GYP domain, capable of degrading the second messenger cyclic di-GMP $[6,10,12,13]$. DSF can bind directly to the $\mathrm{N}$-terminal, 22 amino acid-length sensor region of RpfC and activate RpfC autokinase activity to regulate QS and virulence in $\mathrm{Xcc}$ [14]. RpfH is a putative membrane protein with no known role in DSF signaling [10].

The contribution of DSF/Rpf regulatory system to virulence has been demonstrated in many members of Xanthomonas. For example, DSF signaling in Xcc influences the synthesis of a range of virulence factors including extracellular enzymes such as endoglucanase, protease, and endomannanase, and the xanthan EPS, as well as alterations in biofilm formation $[6,10$, 15]. Specifically, the RpfS- dependent second DSF signaling pathway controls expression of genes involved in type IV secretion and chemotaxis and therefore affects bacterial motility, suggesting a role in the epiphytic phase of the Xcc disease cycle [16]. Similarly, the DSF-mediated QS has been shown involved in early attachment and in planta growth of $\mathrm{Xac}$ in the citrus host during the citrus canker disease cycle [17]. Recent report indicates that the DSF family in $X c c$ elicited plant innate immunity and this effect was suppressed through the secretion of the xanthan exopolysaccharide [18]. DSF also confers a fitness advantage to Xcc during interspecies competition [19].

Transcriptome profile, functional genomics, and proteomic analyses have significantly advanced the understanding of the DSF/Rpf regulatory network and its role in pathogenesis of Xanthomonas. Earlier studies have revealed that the $\mathrm{RpfC/RpfG} \mathrm{two-compo-}$ nent system coordinately regulates the expression of various genes related to virulence via the cyclic di-GMP signaling that activates the transcriptional activators Clp and Zur in Xcc [6, 12, 13, 20]. These include the genes encoding extracellular enzymes, components of type II secretion system (T2SS), components of type III secretion system (T3SS), and the genes involved in EPS production. Comparative transcriptome studies using whole-genome microarray showed that the DSF/Rpf -mediated QS regulation in the citrus canker pathogen X. citri subsp. citri $(\mathrm{Xac})$ is growth phase-dependent, and more genes in the exponential phase are differentially regulated by the $\mathrm{RpfC/RpfG} \mathrm{system} \mathrm{compared} \mathrm{with} \mathrm{in} \mathrm{the} \mathrm{stationary}$ phase [17]. The RpfC/RpfG system-regulated genes include diverse genes involved in chemotaxis and motility, flagellar biosynthesis, production of extracellular enzymes and adhesins, stress tolerance, regulation, transport, and detoxification [17]. There are also some unique genes controlled by RpfF, RpfC or RpfG alone, indicating the complexity of the QS pathway and the involvement of additional DSF signal perception and transduction mechanisms in Xac [17]. Interestingly, recent studies suggested additional signaling outputs from RpfC and an interaction of RpfG with a second unknown sensor [16, 21]. The authors found that DSF and RpfC also regulate expression of a number of genes encoding transcriptional regulator, hydrolase, protease and hypothetical proteins independently of RpfG, and RpfG regulates expression of genes involved in chemotaxis, signal transduction and protein export, independently of $\operatorname{RpfF}$ or $\operatorname{RpfC}[16,21]$. These studies also revealed that $\mathrm{RpfC}$ can recognize other unidentified environmental signals (in addition to DSF) [21] and the DSF signal can be recognized by a second sensor RpfS, a PAS domain-containing histidine kinase that regulates genes involved in type IV secretion and chemotaxis in a pathway independent of RpfC and RpfG [16]. Our knowledge of the protein(s)/regulator(s) acting downstream of RpfS in DSF signal transduction cascades remains limited. In 
addition, the DSF/Rpf system controls three non-coding RNA (ncRNAs) that contribute to virulence in $X c c$ [21].

Comparative proteomic analysis revealed diverse regulatory effects of DSF/Rpf in Xcc on proteins involved in regulation, biosynthesis and intermediary metabolism, stress tolerance, and motility [22]. Similarly, mutation of the rpfF gene has a substantial impact on the proteome of $X$. oryzae pv. oryzicola, affecting proteins involved in a range of functions including nitrogen transfer, protein folding, resistance to oxidative stress and flagellar synthesis [23]. Interestingly, for many of the proteins regulated by the DSF/Rpf system in Xcc, the alteration in abundance was not associated with alteration in transcript level, suggesting that both posttranscriptional regulation and post-translational turnover may occur [22].

Despite the extensive transcriptome analyses of the DSF/Rpf regulatory system in Xanthomonas spp. as stated above, most of which were performed using the bacterium grown under culture media conditions, and knowledge on regulatory effects of the DSF/Rpf system of Xanthomonas spp. during the interaction with host plants is still lacking. The actions of the elements involved in DSF signaling and the role of DSF signal transduction during plant infection remain to be determined from both the pathogen and host aspects. In the present study, we investigated the DSF/Rpf QS regulation in planta during Xac infection of citrus host. Metatranscriptome analysis of the compatible interaction between $X a c$ and citrus was conducted using RNA-Seq to compare the global transcriptomes of wild-type and isogenic $r p f F$ mutant $(\triangle r p f F)$ strains of Xac, as well as the citrus transcriptional patterns in response to their infection. This work provides a comprehensive picture of the genes and traits regulated by the DSF/Rpf QS in Xac in planta and host responses to the DSF-mediated infection.

\section{Methods}

Bacterial strains and growth conditions

Xanthomonas citri subsp. citri (Xac) wild type strain 306 [24] and its $r p f F$ gene deletion ( $\triangle r p f F)$ mutant strain [17] were grown at $28^{\circ} \mathrm{C}$ with shaking at $200 \mathrm{rpm}$. in nutrient broth (NB; Difco, Detroit, MI) containing rifamycin $(50 \mu \mathrm{g} / \mathrm{mL})$. Bacterial growth was measured in a spectrophotometer at $600 \mathrm{~nm}$.

\section{Plant inoculations and sampling of infected leaves}

Plant inoculation was performed as described in our previous work [5]. Briefly, young (about 12-week-old) Duncan grapefruit (Citrus paradise Macfadyen) plants were grown in potting medium/soil in a greenhouse at the Citrus Research and Education Center, Lake Alfred,
FL, USA, and maintained at approximately $25-30{ }^{\circ} \mathrm{C}$ and a $55 \%$ relative humidity until the primary leaves were fully expanded but not fully matured. The bacterial inoculum cells were grown as described above. When the cells reached late-log phase $\left(\mathrm{OD}_{600}=1.0 ; 5 \times 10^{10} \mathrm{cfu} / \mathrm{mL}\right)$, they were collected by centrifugation at $4000 \mathrm{rpm}$ for $15 \mathrm{~min}$. The cell pellets were resuspended in sterilized $0.85 \% \mathrm{NaCl}$, washed, and resuspended in sterilized $0.85 \% \mathrm{NaCl}$ to a final density of $5 \times 10^{6} \mathrm{cfu} / \mathrm{mL}$. To establish in planta populations, bacteria were introduced by infiltration into leaves using a needleless syringe. Infiltrated plants were maintained in the same greenhouse for canker symptom development. All plant inoculations included at least three leaves at a similar developmental stage from each plant, and ten replicate plants were inoculated for each strain. Time- course bacterial growth in planta was tested as described previously [5]. All the tests were repeated three times. Based on the progression of development of canker symptoms, the infected leaves were sampled at 5 days post inoculation (DPI) for RNA extraction. The inoculated leaf area was collected using a cork borer (leaf area, $1 \mathrm{~cm}^{2}$ ) and 10 leaf samples from each biological replicate (three replicates for each treatment) were pooled and immediately frozen in liquid nitrogen, and kept in $-80^{\circ} \mathrm{C}$ until process for RNA isolation.

RNA extraction, library construction and Illumina RNA-seq Total RNA was extracted from leaf samples using RNeasy Plant Mini Kit (Qiagen, Valencia, CA) and contaminated DNA was removed by treatment with RNase-Free DNase Set (Qiagen, Valencia, CA). The quality and quantity of RNA samples were assessed using NanoDrop ND-1000 spectrophotometer (NanoDrop Technologies, Wilmington, DE), Agilent 2100 Bioanalyzer (Agilent Technologies, Santa Clara, CA) and agarose gel electrophoresis. The total RNA was treated with DNase I (New England Biolabs, Ipswich, MA) prior to library construction. The rRNA of plant and bacteria was depleted using Ribo-Zero ${ }^{\mathrm{Tm}}$ rRNA Removal Kits (Plant Leaf) and Ribo-Zero ${ }^{\mathrm{m}}$ rRNA Removal Kits (Bacteria) respectively, according to the manufacturer's instructions (Epicenter Technologies, Madison, WI). Poly (A) + mRNA was purified using Agencourt RNAClean XP Kit (Beckman Coulter Life Sciences, Indianapolis, IN) and fragmented into short pieces. Using these short fragments as templates, first strand cDNA synthesis was conducted using random hexamer-primers and SuperScript ${ }^{\circ}$ II Reverse Transcriptase (Invitrogen, Waltham, MA), and the second-strand cDNA was synthesized using RNase $\mathrm{H}$ (Invitrogen, Waltham, MA) and DNA polymerase I (New England Biolabs, Ipswich, MA). After purification, end repair, and ploy (A) tails add, the cDNA fragments were ligated to 
sequencing adapters. Then fragments of an appropriate size were purified and amplified by PCR to produce the final library. Finally, the cDNA libraries were loaded onto the flow cell channels of an Illumina HiSeqTM 2000 platform for paired-end $90 \mathrm{bp} \times 2$ sequencing at the Beijing Genomics Institute (BGI), Hongkong, China. Clean reads were obtained after removing reads containing adaptor sequences. The RNA reads have been deposited at NCBI under the bioproject No. PRJNA421992 with the SRA accession no. SRP126698.

\section{Reads mapping and differential expression analysis}

The clean reads were firstly aligned to the $X a c$ strain 306 genome (https://www.ncbi.nlm.nih.gov/nuccore/ AE008923.1/) [24] using bowtie2 [25] with default parameters. The in planta differential expressed genes between wild type Xac 306 and $\triangle r p f F$ mutant strains were identified using DESeq2 $\mathrm{R}$ package [26] with the following cutoffs: |fold change $\mid \geq 2$ and agjust $-P \leq 0.05$. After aligned to Xac strain 306 genome, the remaining reads from each sample were analyzed mainly following the tuxedo pipeline [27]. Briefly, the reads were aligned to the sweet orange genome [28] using Tophat (v2.0.13) [29], and the generated alignments were fed to Cufflinks (v2.2.1) for transcript assembly [30]. The assemblies were combined with the sweet orange annotations using the cuffmerge algorithm and then fed to the cuffdiff 2 for differentially expressed gene calling. Only the genes with $\mid$ fold change $\mid \geq 2$, q-value $\leq 0.05$ and FPKM $\geq 1$ were considered as significantly differentially expressed genes (DEGs) between wild type strain infected and $\Delta \mathrm{rpf}$ mutant strain infected plants. The MapMan gene functional categories were assigned to the DEGs using Mercator $[30,31]$ and the differentially regulated bins were identified by using MapMan [32].

\section{Functional annotation and classification}

For citrus DEGs, the corresponding reference ID were obtained by blasting them to CitrusPLEX in plant expression database (PLEXdb, http://www.plexdb.org/ plex.php?database=Citrus) [33]. Gene Ontology (GO) enrichment analysis of functional significance was applied to map all DEGs to terms in the agriGO (http:// bioinfo.cau.edu.cn/agriGO/) database [34], looking for significantly enriched GO terms in DEGs. For bacterial DEGs, Clusters of Orthologous Groups (COG, https:// www.ncbi.nlm.nih.gov/COG/) enrichment analysis was performed by comparing the prevalence of DEGs assigned to a specific COG category to the prevalence of genes in the whole genome assigned to that COG category with a Fisher's exact test.

\section{Validation of RNA-seq results by qRT-PCR}

To verify the RNA-seq result, qRT-PCR assays were conducted using the same set of RNA samples as for RNA-seq analysis. The aliquoted RNA sample $(1 \mu \mathrm{g})$ used for RNA-seq was reverse transcribed using a QuantiTect Reverse Transcription kit with random hexamer primers (Qiagen, Valencia, CA) for two-step qRT-PCR. The gene specific primers (Additional file 1: Table S1) were designed to generate amplicons of 70 to $150 \mathrm{bp}$ based on the DEGs sequences of citrus plant and Xac strain 306. qRT-PCR was conducted using QuantiTect SYBR Green PCR Kit (Qiagen, Valencia, CA) and the 7500 fast real-time PCR system (Applied Biosystems, Foster City, CA). Melting curve analysis of the PCR products was performed at the end of each PCR cycle to confirm the amplicon specificity. The housekeeping gene CtGAPDH [35] and gyrA [5] was used as plant and bacterial endogenous control, respectively. All reactions were repeated with three independent biological replicates and two technical replicates. The relative fold change in target gene expression was calculated by using the formula $2^{-\triangle \Delta \mathrm{CT}}[36]$.

\section{Statistical analysis}

Quantitative data were expressed as mean \pm S.E.M. Statistical differences were evaluated through $t$-test and the level of statistically significant difference was set at $P<0.05$. All statistics were conducted using SAS 9.1.3.

\section{Results}

\section{Canker progression and symptoms in inoculated citrus plants}

Duncan grapefruit (Citrus paradisi Macfadyen) seedlings were inoculated with Xac wild type strain 306 and its DSF deficient $(\triangle r p f F)$ mutant strain for the development of typical symptoms of citrus canker. The first visible symptom, a water soaking area of the inoculated leaf, was observed at 5 days post inoculation (DPI). Within 14 DPI, typical symptoms of the canker disease were recorded (Fig. 1a): inoculated areas were characterized with water soaking, and then exhibited hyperplasia and hypertrophic, necrotic, erumpent lesions, as evidenced by the raised pustules. The $\Delta r p f F$ mutant produced weaker water soaking phenotypes compared to wild type strain 306 at 5 DPI under the tested conditions; and this becomes more evident at 7DPI and until 9 DPI (Fig.1a). However, the bacterial populations of the $\triangle r p f F$ mutant in planta were not significantly lower than the wild type strain (Fig. 1b).

\section{Sequencing the early citrus canker transcriptome}

As the differences in the development of canker symptoms only were recorded in early stages of disease development (formation of water-soaking phenotypes) between 

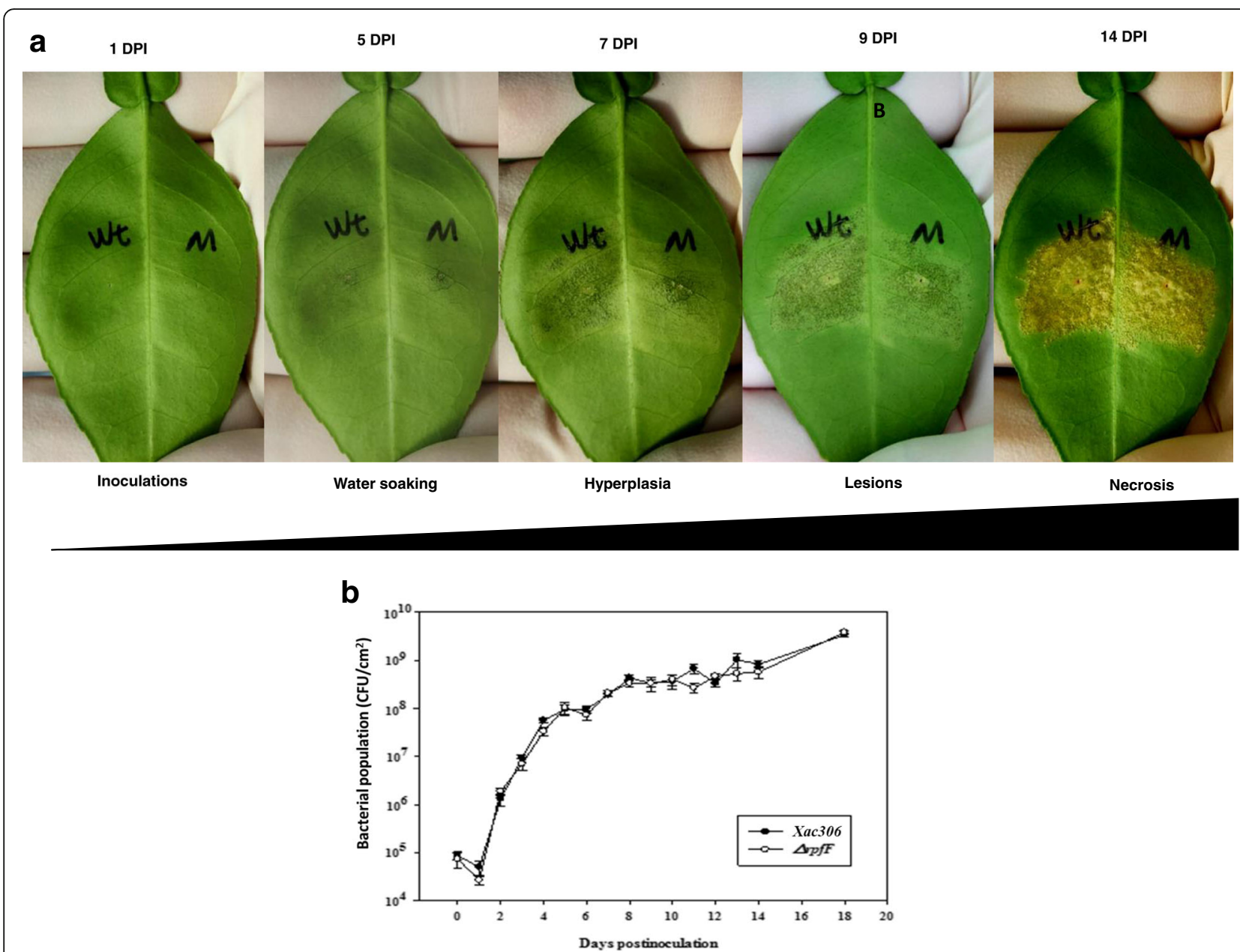

Fig. 1 Citrus canker disease development in Xanthomonas citri inoculated Duncan grapefruit plants. a Representative leaves from ten replicates to show the development of canker symptoms on leaves inoculated with Xanthomonas citri subsp. citri wild type (Wt) strain 306 and its $\Delta r p f F$ mutant $(\mathrm{M})$ with bacterial solutions $\left(5 \times 10^{6} \mathrm{CFU} / \mathrm{ml}\right)$ by infiltration using needleless syringes and photographed at different days post inoculation (DPI). b Bacterial population growth in in Duncan grapefruit leaves inoculated with bacteria $\left(5 \times 10^{6} \mathrm{CFU} / \mathrm{ml}\right)$ at different days post inoculation. Error bars represent standard deviation. All the experiments were repeated three times

the wild type Xac and $\Delta \mathrm{rpfF}$ mutant (Fig. 1a), we speculated that the DSF/Rpf QS play certain role(s) in early stages of the Xac-citrus compatible interaction. Therefore, the early canker transcriptome during the formation of water-soaking phenotypes was profiled at 5 DPI.A total of 227 million and 278 million paired-end reads for wild type Xac strain 306 infected and the $\triangle r p f F$ mutant infected plants were produced respectively (Additional file 2: Table S2). All reads were aligned against the Xac strain 306 genome [24]. For each RNA-seq library, $2.4-5.5 \%$ of the reads mapped to the Xac 306 reference. Then the remaining Xac strain 306-unaligned reads were mapped against the sweet orange (Citrus sinensis) genome [28], for the analysis of the citrus host transcriptome. A significant fraction of the Xac306-unaligned reads (63-68\%) from both wild type $X a c$ infected and $\Delta r p f F$ mutant infected libraries mapped to the sweet orange reference (Additional file 2: Table S2). Finally, of the 4374 Xac genes, 202 (4.5\%) were determined as significantly differentially expressed genes (DEGs) [a minimum absolute value of a log2-fold change greater than 1 (equivalent to two-fold)] between wild type Xac 306 and $\triangle r p f F$ mutant strains in the conditions analyzed (Additional file 3: Table S3). Among them, 138 were upregulated in Xac wild type strain 306 compared to $\Delta r p f F$ mutant and 64 were downregulated. Of the 29,445 citrus (sweet orange) genes, 1946 genes were identified as significantly DEGs between wild type Xac 306 infected and $\Delta r p f F$ mutant strain infected plants, with 708 genes upregulated and 1238 downregulated in the wild type Xac 306 infected plants compared to $\triangle r p f F$ mutant strain infected plants (Additional file 4: Table S4). 
To validate the gene expression values obtained by RNA-seq, the expression of $40 \mathrm{Xac}$ genes and 33 citrus genes (Additional file 1: Table S1) in the RNA samples used in RNA-seq analysis were analyzed by qRT-PCR assays. A strong correlation $\left(\mathrm{R}^{2}=0.9141\right.$ for $\mathrm{Xac}$ gene expression; $R^{2}=0.9011$ for citrus gene expression) were observed between the data produced by the two approaches (Fig. 2a-b), demonstrating the reliability of the results obtained.

Functionally categorizing of Xac genes regulated by the DSF/Rpf-mediated QS system during early stages of host infection

The 202 DEGs of Xac were subject to functionally categorizing with enrichment analyses of clusters of orthologous groups (COGs). The results showed that overrepresented COGs terms were mostly related to 'Carbohydrate transport and metabolism' (39 members, 16.3\%), 'Amino acid transport and metabolism' (29 members, 14.4\%), 'Inorganic ion transport and metabolism' (21 members, 10.4\%), and 'Cell wall/membrane/envelope biogenesis' (19 members, 9.41\%) (Fig. 3). Other enriched terms included 'Lipid transport and metabolism,' 'Energy production and conversion,' 'Post-translational modification, protein turn over, and chaperones', 'signal transduction mechanisms,' 'Transcription', and 'General function prediction only'. In addition, the genes annotated as hypothetical proteins were assigned to the 'Function unknown' group.
DSF/Rpf-mediated QS regulates stress tolerance of Xac during early stages of host infection

A total 12 genes encoding enzymes involved in detoxification and stress tolerance of $\mathrm{Xac}$ at early stages of host infection were differentially regulated by DSF/Rpf-mediated QS (Table 1). Of these, the genes coding for a putative arabinose efflux permease belonging to the Major Facilitator Superfamily (MFS) transporter for sugar/drug (araJ /XAC1363), for a drug resistance translocase (yieO XAC2494), for an endoproteinase (argC/XAC2992), and for trehalose biosynthesis (XAC0425 and XAC0429) were upregulated by $\geq 2$-fold on average. Bacterial endoproteinases are able to degrade host defense proteins $[37,38]$, and trehalose protects bacterial cells from osmotic and oxidative stresses $[39,40]$. The katE gene (XAC1211) encoding a catalase important for hydrogen peroxide torelance in Xac [41], was also upregulated by 2-fold.

DSF/Rpf -mediated QS is implicated in the regulation of nutrition utilization of Xac during early stages of host infection

A significant portion of the Xac in planta transcriptome regulated by DSF/Rpf -mediated QS is dedicated to nutrition utilization (Fig. 3). Of the 39 genes involved in carbohydrate uptake and metabolism, 14 were positively regulated by DSF/ Rpf -mediated QS, while 25 were negatively regulated (Table 2). The carbohydrate genes upregulated by DSF/Rpf mediated QS included those encoding cellulose endoglucanase (egl/XAC0029 and engXCA/XAC0612), glycosyl transferase
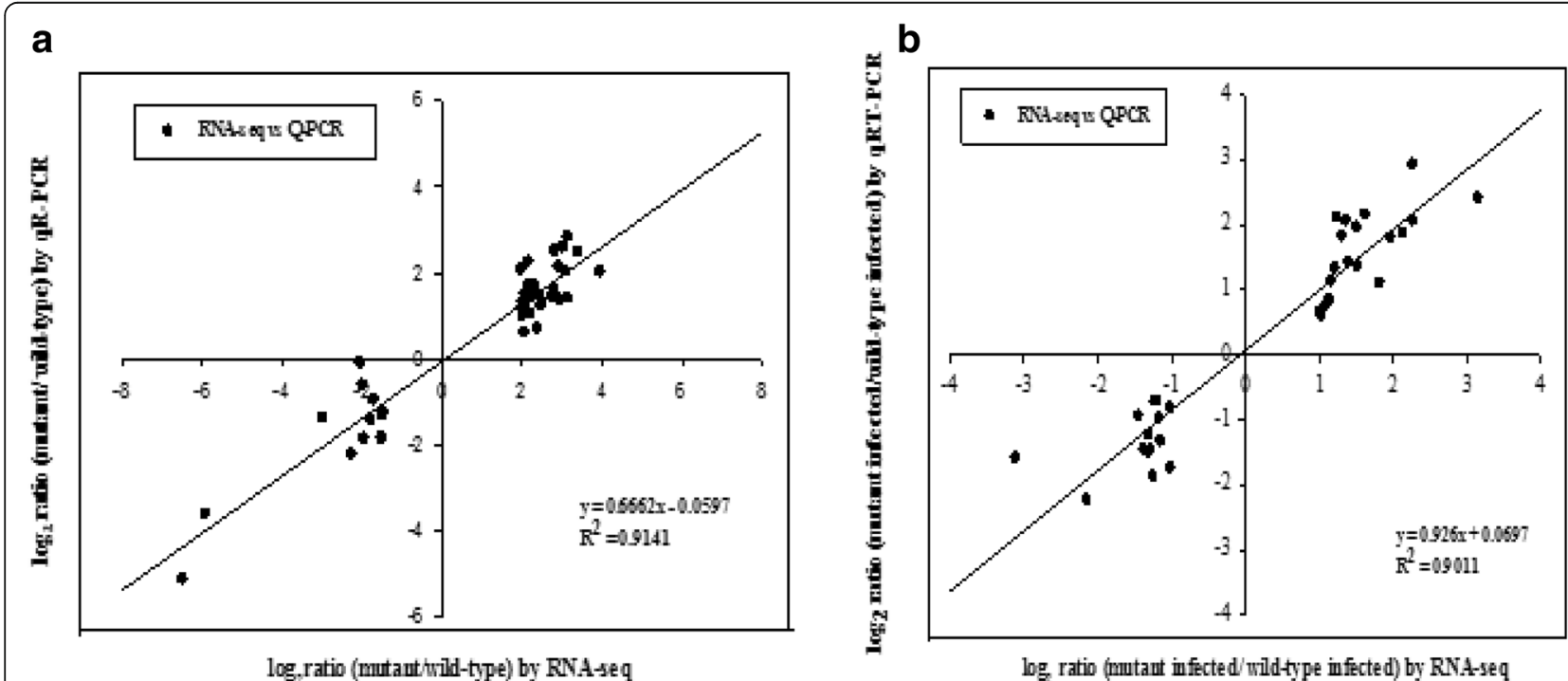

Fig. 2 Correlation analysis of expression levels of selected bacterial genes and citrus genes determined by RNA-seq and RT-qPCR. a Comparison of RNA-seq and qRT-PCR data for differentially expressed genes (DEGs) in Xanthomonas citri subsp. citri. Fold changes were calculated for 40 bacterial genes and a high correlation $\left(R^{2}>0.90\right)$ was observed between the results obtained using the two techniques. $\mathbf{b}$ Comparison of RNAseq and qRT-PCR data for DEGs in citrus. Fold changes were calculated for 33 citrus genes and a high correlation $\left(R^{2}>0.90\right)$ was observed between the results obtained using the two techniques 


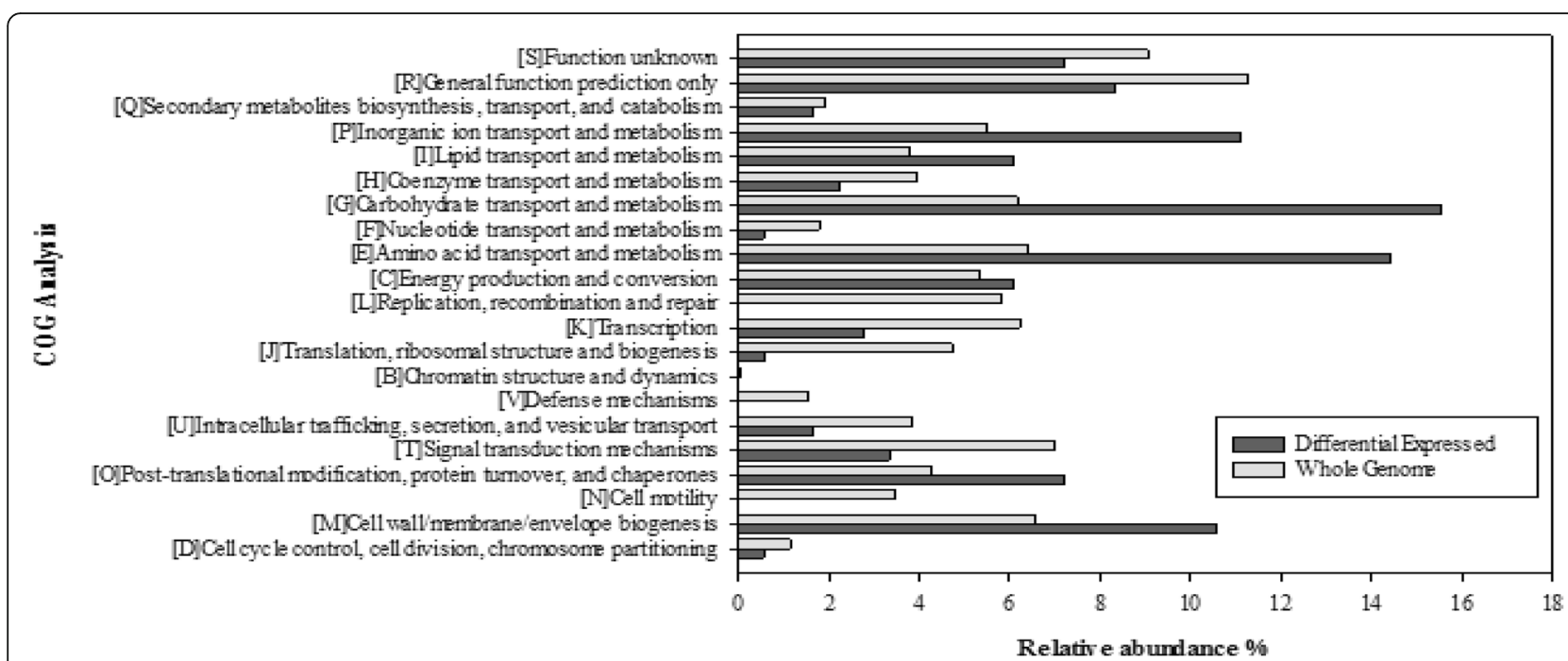

Fig. 3 Distribution of differentially expressed genes (DEGs) of Xanthomonas citri subsp. citri in COG functional categories. The $x$-axis represents the relative abundance (\%) of DEGs and all the genes in the bacterial whole genome in each COG category. The $y$-axis represents the functional classification each COG category

(gtrB/XAC1038/XAC2125, XAC3533, and ugt/XAC3921), glycosyl hydrolase (XAC3073), glycogen synthase $(g l g A$ /XAC0425 and $g \lg Y / \mathrm{XAC0429),} \mathrm{glucose} \mathrm{dehydrogenase}$ ( $g c d / X A C 1633 / X A C 3212)$, glucokinase ( $g l k / X A C 3120)$, and transporter (araJ/XAC1363 and yieO/XAC2494). In contrast, the expressions of fruBK and fruA encoding

Table 1 List of genes related to stress tolerance in Xac regulated by DSF/Rpf-mediated QS during early stages of host infection

\begin{tabular}{|c|c|c|c|}
\hline Locus tag & $\begin{array}{l}\text { Gene } \\
\text { name }\end{array}$ & $\begin{array}{l}\text { Log }_{2} \text { Fold } \\
\text { Change } \\
\text { (Wt/ } / \text { rpff) }\end{array}$ & Annotation/ Protein function \\
\hline XAC0425 & $g \lg A$ & 1.03 & $\begin{array}{l}\text { glycogen synthase (trehalose } \\
\text { biosynthesis) }\end{array}$ \\
\hline XAC0429 & $\operatorname{glg} Y$ & 1.04 & malto-oligosyltrehalose synthase \\
\hline XAC1211 & katE & 1.00 & catalase \\
\hline XAC1363 & araj & 1.32 & $\begin{array}{l}\text { arabinose efflux permease, MFS } \\
\text { transporter }\end{array}$ \\
\hline XAC1927 & $a s / B$ & 1.14 & $\begin{array}{l}\text { Fe-S oxidoreductase, stress- } \\
\text { responsive }\end{array}$ \\
\hline XAC2494 & yieO & 1.29 & drug resistance translocase \\
\hline XAC2992 & $\arg C$ & 2.98 & $\begin{array}{l}\text { endoproteinase } \mathrm{Arg}-\mathrm{C} \text {, degrading } \\
\text { host defense proteins }\end{array}$ \\
\hline XAC4259 & $b / c$ & 1.05 & $\begin{array}{l}\text { lipocalin, involved in detoxification } \\
\text { processes }\end{array}$ \\
\hline XAC0906 & $a h p F$ & -1.01 & $\begin{array}{l}\text { alkyl hydroperoxide reductase } \\
\text { scavenging } \mathrm{H}_{2} \mathrm{O}_{2}\end{array}$ \\
\hline XAC0907 & $a h p C$ & -1.14 & $\begin{array}{l}\text { alkyl hydroperoxide reductase } \\
\text { scavenging } \mathrm{H}_{2} \mathrm{O}_{2}\end{array}$ \\
\hline XAC3486 & fabG & -3.14 & $\begin{array}{l}\text { 3-ketoacyl-ACP reductase, induced } \\
\text { by nutrient limit conditions }\end{array}$ \\
\hline XAC4361 & $t t u B$ & -1.51 & MFS transporter \\
\hline
\end{tabular}

components of a fructose-specific phosphoenolpyruvate (PEP): carbohydrate phosphotransferase system (PTS) were downregulated.

For the genes involved in uptake and metabolism of amino acids, most (23 out of 29) were downregulated by DSF/Rpf QS in planta, while a small portion (6/29) were upregulated (Table 2). Among the downregulated genes, some are involved in the biosynthesis of asparagine (asnB/XAC1433), tyrosine (phhA/XAC0174), glutamine

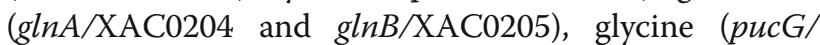
$\mathrm{XAC0300}$ and amaB/XAC0301), threonine (thrAB/ XAC1820, XAC1821, and thrC/XAC1823), histidine (hisGDCBHAFI/XAC1828-1835), and biosynthesis of isoleucine, leucine, and valine (ilvCGM, tdcB, leuA/ XAC3451-3455). Over-presented in the up-regulated genes are those for biosynthesis of methionine (metE/ $X A C 0306)$ and lysine (dapA/XAC2547), for a metalloproteinase (XAC0465), and for glycine biosynthesis and cleavage ( $g c v P / \mathrm{XAC1214})$. Remarkably, the urea amidolyase and an allophanate hydrolase, which catalyze the release of ammonia from urea, showed distinctive expression levels ( $\log _{2}$ Fold Change 25.9 ) upregulated by DSF/RPF QS in Xac during host infection.

Eleven differentially expressed genes were related to inorganic ion transport and metabolism in Xac during host infection (Table 2). Remarkably, the two genes (phoX/ XAC1578 and oprO/XAC1579) encoding phosphate transporter proteins were upregulated by an average of 2.6-fold by DSF/Rpf QS during infection. The genes for siderophore biosynthesis (entF/XAC3922) and for iron storage protein in the bacterioferritin family ( $b f r /$ XAC1149) [42] were upregulated two-fold or more (Table 3). Six genes encoding TonB-dependent outer-membrane 
Table 2 List of genes involved in nutrient transport or metabolism in Xac regulated by DSF/Rpf-mediated QS during pathogenic process

\begin{tabular}{|c|c|c|c|}
\hline Locus tag & $\begin{array}{l}\text { Gene } \\
\text { name }\end{array}$ & $\begin{array}{l}\text { Log }_{2} \text { Fold } \\
\text { Change } \\
\text { (Wt/ArpfF) }\end{array}$ & Annotation/ Protein function \\
\hline
\end{tabular}

\begin{tabular}{|c|c|c|c|}
\hline \multicolumn{4}{|c|}{ Carbohydrates transport and metabolism } \\
\hline XAC0029 & egl & 1.34 & cellulase \\
\hline XAC0425 & $g \lg A$ & 1.03 & glycogen synthase \\
\hline XAC0429 & $\operatorname{glg} Y$ & 1.04 & malto-oligosyltrehalose synthase \\
\hline XAC0612 & engXCA & 1.53 & cellulase \\
\hline XAC1038 & gtr $B$ & 1.12 & glycosyl transferase \\
\hline XAC1363 & araj & 1.32 & MFS transporter \\
\hline XAC1633 & gcd & 2.06 & glucose dehydrogenase \\
\hline XAC2125 & gtrB & 1.07 & glycosyl transferase \\
\hline XAC2494 & yieO & 1.29 & drug resistance translocase \\
\hline XAC3073 & & 1.00 & $\begin{array}{l}\text { GH18 family; chitinase-like glycosyl } \\
\text { hydrolase }\end{array}$ \\
\hline XAC3120 & $g / k$ & 1.36 & glucokinase \\
\hline XAC3212 & gcd & 1.05 & glucose dehydrogenase \\
\hline XAC3533 & & 1.23 & Glycosyltransferase, GT2 family \\
\hline XAC3921 & ugt & 1.52 & glucosyltransferase \\
\hline XAC0217 & $\lg t B$ & -1.06 & glycosyltransferase \\
\hline XAC0299 & & -2.16 & polysaccharide /chitin deacetylase \\
\hline XAC0575 & $\operatorname{gan} B$ & -1.98 & $\begin{array}{l}\text { arabinogalactan endo-1,4-beta- } \\
\text { galactosidase }\end{array}$ \\
\hline XAC1286 & $a b f A$ & -1.09 & alpha-L-arabinofuranosidase \\
\hline XAC1308 & bga & -1.18 & beta-galactosidase \\
\hline XAC1309 & galA & -1.49 & $\begin{array}{l}\text { arabinogalactan endo-1,4-beta- } \\
\text { galactosidase }\end{array}$ \\
\hline XAC1556 & fucP & -1.43 & glucose-galactose transporter \\
\hline XAC1557 & scrk & -1.49 & fructokinase \\
\hline XAC1558 & & -1.46 & $\begin{array}{l}\text { putative } \mathrm{N} \text {-acylglucosamine } \\
\text { 2-epimerase }\end{array}$ \\
\hline XAC1770 & celA & -1.03 & cellulase \\
\hline XAC1771 & & -1.02 & sialic acid-specific 9-O-acetylesterase \\
\hline XAC1793 & celD & -2.46 & glucan 1,4-beta-glucosidase \\
\hline XAC1794 & folk & -2.38 & sodium/glucose cotransport protein \\
\hline XAC1812 & hmsF & -1.72 & $\begin{array}{l}\text { HmsF protein /Polysaccharide } \\
\text { deacetylase }\end{array}$ \\
\hline XAC1813 & hmsH & -2.06 & $\begin{array}{l}\text { HmsH protein /substrate-specific } \\
\text { transmembrane transporter }\end{array}$ \\
\hline XAC2501 & fruB & -1.73 & multiphosphoryl transfer protein \\
\hline XAC2502 & fruk & -1.68 & 1-phosphofructokinase \\
\hline XAC2503 & fruA & -1.79 & $\begin{array}{l}\text { PTS system fructose-specific } \\
\text { transporter subunit II }\end{array}$ \\
\hline XAC3474 & cit1 & -1.08 & citrate carrier protein \\
\hline XAC3487 & $c e b R$ & -2.20 & transcriptional regulator \\
\hline XAC3489 & fyuA & -1.49 & $\begin{array}{l}\text { TonB-dependent sucrose outer } \\
\text { membrane transporter }\end{array}$ \\
\hline
\end{tabular}

Table 2 List of genes involved in nutrient transport or metabolism in Xac regulated by DSF/Rpf-mediated QS during pathogenic process (Continued)

\begin{tabular}{llll}
\hline Locus tag & $\begin{array}{l}\text { Gene } \\
\text { name }\end{array}$ & $\begin{array}{l}\text { Log }_{2} \text { Fold } \\
\text { Change } \\
\text { (Wt/_rpff })\end{array}$ & Annotation/ Protein function \\
\hline XAC3490 & -1.22 & amylosucrase or alpha amylase \\
XAC4195 & ndvB/ \\
celAP & -1.23 & $\begin{array}{l}\text { NdvB protein/ cellobionic acid } \\
\text { phosphorylase }\end{array}$ \\
XAC4355 & -1.34 & Glyco_hydro like \\
XAC4361 ttuB & -1.51 & MFS transporter
\end{tabular}

Amino acid transport and metabolism

\begin{tabular}{|c|c|c|c|}
\hline XAC0336 & metE & 1.72 & $\begin{array}{l}\text { 5-methyltetrahydropteroyl } \\
\text { triglutamate-methyltransferase }\end{array}$ \\
\hline XAC0465 & & 1.37 & metalloproteinase \\
\hline XAC1214 & $g \subset v P$ & 1.09 & glycine dehydrogenase \\
\hline XAC2547 & $\operatorname{dapA}$ & 1.06 & dihydrodipicolinate synthetase \\
\hline XAC4326 & uahA & 6.50 & urea amidolyase \\
\hline XAC4327 & uahA & 5.92 & allophanate hydrolase \\
\hline XAC0174 & phhA & -1.14 & phenylalanine 4-monooxygenase \\
\hline XAC0204 & $g \ln A$ & -3.39 & glutamine synthetase \\
\hline XAC0205 & $g \ln B$ & -3.01 & nitrogen regulatory protein P-\| \\
\hline XAC0206 & $a m t B$ & -2.78 & ammonium transporter \\
\hline XAC0300 & pucG & -2.08 & serine-pyruvate aminotransferase \\
\hline XAC0301 & $a m a B$ & -2.72 & allantoate amidohydrolase \\
\hline XAC1433 & $a s n B$ & -1.19 & asparagine synthetase B \\
\hline XAC1820 & thrA & -1.24 & $\begin{array}{l}\text { bifunctional aspartokinase I/ } \\
\text { homoserine dehydrogenase I }\end{array}$ \\
\hline XAC1821 & thrB & -1.20 & homoserine kinase \\
\hline XAC1823 & thre & -1.24 & threonine synthase \\
\hline XAC1828 & hisG & -2.32 & ATP phosphoribosyltransferase \\
\hline XAC1829 & hisD & -2.02 & histidinol dehydrogenase \\
\hline XAC1830 & hisC & -1.94 & $\begin{array}{l}\text { histidinol-phosphate } \\
\text { aminotransferase }\end{array}$ \\
\hline XAC1831 & hisB & -1.73 & $\begin{array}{l}\text { imidazole glycerol-phosphate } \\
\text { dehydratase/phosphatase }\end{array}$ \\
\hline XAC1832 & hisH & -1.36 & $\begin{array}{l}\text { imidazole glycerol phosphate } \\
\text { synthase subunit HisH }\end{array}$ \\
\hline XAC1833 & hisA & -1.61 & $\begin{array}{l}\text { 1-(5-phosphoribosyl)-5- imidazole- } \\
\text { 4-carboxamide isomerase }\end{array}$ \\
\hline XAC1834 & hisF & -1.51 & $\begin{array}{l}\text { imidazole glycerol phosphate } \\
\text { synthase subunit HisF }\end{array}$ \\
\hline XAC1835 & hisl & -1.12 & phosphoribosyl-AMP cyclohydrolase \\
\hline XAC3451 & ilve & -2.15 & ketol-acid reductoisomerase \\
\hline XAC3452 & $i l v G$ & -1.69 & $\begin{array}{l}\text { acetolactate synthase } 2 \text { catalytic } \\
\text { subunit }\end{array}$ \\
\hline XAC3453 & $i l v M$ & -1.49 & $\begin{array}{l}\text { acetolactate synthase isozyme II small } \\
\text { subunit }\end{array}$ \\
\hline XAC3454 & $t d c B$ & -1.71 & threonine dehydratase \\
\hline XAC3455 & leuA & -1.22 & 2-isopropylmalate synthase \\
\hline
\end{tabular}

Lipid transport and metabolism 
Table 2 List of genes involved in nutrient transport or metabolism in Xac regulated by DSF/Rpf-mediated QS during pathogenic process (Continued)

\begin{tabular}{|c|c|c|c|}
\hline Locus tag & $\begin{array}{l}\text { Gene } \\
\text { name }\end{array}$ & $\begin{array}{l}\text { Log }_{2} \text { Fold } \\
\text { Change } \\
\text { (Wt/Arpff) }\end{array}$ & Annotation/ Protein function \\
\hline XAC0159 & estAl & 1.15 & carboxylesterase type B \\
\hline XAC1037 & & 1.12 & membrane protein \\
\hline XAC1316 & $m m s B$ & 1.03 & $\begin{array}{l}\text { 3-hydroxyisobutyrate } \\
\text { dehydrogenase }\end{array}$ \\
\hline XAC0375 & aes & -1.42 & lipase \\
\hline XAC2012 & fadA & -1.25 & acetyl-CoA acetyltransferase \\
\hline XAC2013 & $\mathrm{fadB}$ & -1.66 & 3-hydroxyacyl-CoA dehydrogenase \\
\hline XAC3300 & est $A$ & -1.10 & esterase \\
\hline XAC3486 & $f a b G$ & -3.14 & 3-ketoacyl-ACP reductase \\
\hline XAC3959 & & -1.69 & Acyl-CoA delta-9-desaturase \\
\hline
\end{tabular}

Inorganic ion transport and metabolism

\begin{tabular}{|c|c|c|c|}
\hline XAC1578 & phoX & 1.34 & phosphate-binding protein \\
\hline XAC1579 & oprO & 1.50 & polyphosphate-selective porin O \\
\hline XAC0296 & & -2.50 & monoxygenase \\
\hline XAC0310 & $\operatorname{van} B$ & -3.94 & $\begin{array}{l}\text { vanillate O-demethylase } \\
\text { oxidoreductase }\end{array}$ \\
\hline XAC0311 & $\operatorname{van} A$ & -3.07 & $\begin{array}{l}\text { vanillate O-demethylase } \\
\text { oxygenase }\end{array}$ \\
\hline XAC0742 & & -1.45 & RenB containg protein \\
\hline XAC0999 & cirA & -1.04 & colicin I receptor \\
\hline XAC3168 & $b f e A$ & -1.55 & ferric enterobactin receptor \\
\hline XAC3169 & $b f e A$ & -1.17 & ferric enterobactin receptor \\
\hline XAC3472 & oprO & -1.82 & polyphosphate-selective porin O \\
\hline XAC3484 & oprO & -2.90 & porin \\
\hline
\end{tabular}

receptors involved in siderophore-mediated ferric iron uptake by $X a c$ [42, 43], including $f e c A / X A C 0690$, btuB/ $\mathrm{XAC1310}$, and fyuA/XAC3489, were downregulated two-fold on average. In addition, the two genes coding for ferric enterobactin receptors involved in siderophore uptake (bfeA/ XAC3168 and XAC 3169) were also downregulated two-fold on average (Table 3).

\section{Genes for signal transducers and/or transcriptional regulators regulated by DSF/Rpf-mediated QS in Xac during early stages of host infection}

The expression of 12 genes coding for signal transducers and/or transcriptional regulators in Xac were differentially regulated by DSF/Rpf-mediated QS (Table 4). Of these, two genes were upregulated and 10 genes were downregulated. The two upregulated genes were $X A C 1328$ and XAC3927, encoding a putative CheY-like superfamily protein and serine/threonine protein kinase respectively, both are of signal transducer activity.
Table 3 List of ferric iron uptake genes in Xac regulated by DSF/RPF during pathogenic process

\begin{tabular}{|c|c|c|c|}
\hline $\begin{array}{l}\text { Locus } \\
\text { tag }\end{array}$ & $\begin{array}{l}\text { Gene } \\
\text { name }\end{array}$ & 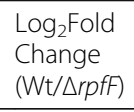 & Annotation/ Protein function \\
\hline XAC1149 & $b f r$ & 1.01 & Bacterioferritin, iron storage \\
\hline XAC3922 & entF & 1.42 & $\begin{array}{l}\text { ATP-dependent serine activating } \\
\text { enzyme (nonribosomal peptide } \\
\text { synthetases, siderophore biosyntensis) }\end{array}$ \\
\hline XAC0690 & fecA & -1.08 & $\begin{array}{l}\text { TonB-dependent outer membrane } \\
\text { receptor }\end{array}$ \\
\hline XAC1310 & $b t u B$ & -2.07 & $\begin{array}{l}\text { TonB-dependent outer membrane } \\
\text { receptor }\end{array}$ \\
\hline XAC1768 & fhuA & -1.19 & $\begin{array}{l}\text { TonB-dependent outer membrane } \\
\text { receptor }\end{array}$ \\
\hline XAC1769 & cirA & -1.71 & $\begin{array}{l}\text { TonB-dependent outer membrane } \\
\text { receptor }\end{array}$ \\
\hline XAC2312 & & -1.27 & $\begin{array}{l}\text { TonB-dependent outer membrane } \\
\text { receptor }\end{array}$ \\
\hline XAC3489 & fyuA & -1.49 & $\begin{array}{l}\text { TonB-dependent outer membrane } \\
\text { receptor }\end{array}$ \\
\hline XAC3168 & bfeA & -1.55 & $\begin{array}{l}\text { Ferric enterobactin receptor, } \\
\text { siderophore }\end{array}$ \\
\hline XAC3169 & $b f e A$ & -1.18 & $\begin{array}{l}\text { Ferric enterobactin receptor, } \\
\text { siderophore }\end{array}$ \\
\hline
\end{tabular}

Among those genes downregulated were the two genes $n t r B$ (XAC0207) and ntrC (XAC0208) encoding the $\mathrm{NtrB} / \mathrm{C}$ two-component system, which interacts with the $\mathrm{RpfC/G}$ system responding to DSF signal to regulate sigma54-dependent promoters in vitro [44]. In addition, the two-component sensor genes $t c t E$ (XAC3482) and $\mathrm{XAC} 3720$, the transcriptional regulator genes acoR (XAC0654), tetR (XAC2014), iscR (XAC 2934), and cebR (XAC3487), the AbrB ambiactive repressor and activator (XAC1883), and the Trp operon repressor gene (trpR/ XAC1827) were downregulated by the DSF/Rpf -mediated QS. The homologues of these signal transduction and transcription factors constitute regulators of virulence and adaptation factors in many bacteria, including the human bacterial pathogens enterotoxigenic $E$. coli [45] and $P$. aeruginosa [46], and the model organism Bacillus subtilis strain 168 [47]. For example, the IscR transcriptional repressor in E. coli negatively controls the type I fimbriae colonization factor synthesis and biofilm formation in response to both iron limitation and oxidative stress [45]. The trp repressor negatively regulates expression of genes involved in tryptophan biosynthesis, transport, and metabolism in response to intracellular levels of tryptophan, but also regulates transcription initiation in several other operons related to tryptophan metabolism that are important for expression of virulence factors in E. coli and $P$. 
Table 4 Summary of Xac DEGs coding for signal transduction and transcriptional factors regulated by DSF/Rpf-mediated QS during pathogenic process

\begin{tabular}{|c|c|c|c|}
\hline $\begin{array}{l}\text { Locus } \\
\text { tag }\end{array}$ & $\begin{array}{l}\text { Gene } \\
\text { name }\end{array}$ & 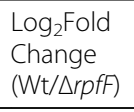 & Annotation/ Protein function \\
\hline XAC1328 & & 1.07 & CheY-like protein superfamily \\
\hline XAC3927 & & 1.04 & serine/threonine protein kinase \\
\hline XAC0207 & $n t r B$ & -1.28 & $\begin{array}{l}\text { two-component system sensor } \\
\text { protein }\end{array}$ \\
\hline XAC0208 & $n t r C$ & -1.21 & $\begin{array}{l}\text { two-component system regulatory } \\
\text { protein }\end{array}$ \\
\hline XAC0654 & $a c o R$ & -1.27 & transcriptional regulator AcoR \\
\hline XAC1827 & & -2.41 & $\begin{array}{l}\text { hypothetical protein/ Trp repressor } \\
\text { protein (represses transcription } \\
\text { of the Trp operon) }\end{array}$ \\
\hline XAC1883 & & -1.00 & $\begin{array}{l}\text { hypothetical protein/ AbrB domain } \\
\text { containing transcriptional regulator }\end{array}$ \\
\hline XAC2014 & & -1.29 & TetR family transcriptional regulator \\
\hline XAC2934 & iscR & -1.02 & $\begin{array}{l}\text { hypothetical protein/ Iron-sulfur } \\
\text { cluster regulator IscR (Fe-S assembly } \\
\text { SUF system transcriptional regulator) }\end{array}$ \\
\hline XAC3482 & tctE & -1.02 & $\begin{array}{l}\text { two-component system sensor } \\
\text { protein }\end{array}$ \\
\hline XAC3487 & $c e b R$ & -2.20 & transcriptional regulator \\
\hline XAC3720 & & -1.18 & $\begin{array}{l}\text { hypothetical protein/ putative } \\
\text { two-component system sensor kinase }\end{array}$ \\
\hline
\end{tabular}

aeruginosa [46]. Thus, they might function as regulators of virulence and adaptation factors in Xac by modulating biofilm formation and adhesion factor production, which are crucial for attachment and colonization of the tissues and for consequent invasion [17].

\section{Putative function of the hypothetical protein encoding genes within the DSF/Rpf-mediated QS regulon in planta} BLASTx analysis showed that 39 of the 44 genes within the DSF/Rpf QS regulon encoding hypothetical proteins had significant similarities only to sequences in bacteria within the Xanthomonas genus. Based on sequence similarity and conserved domain detected, we defined putative functions for 24 of the 44 genes, which are potentially involved in bacterial adaptation and pathogenesis (Table 5). Some of these genes encode proteins with recognized roles in bacterial pathogenesis, such as members of the cell surface adhesion protein families (XAC3546) and chemotaxis protein families (XAC3753 and XAC3754). Interestingly, the genes encoding stress-induced protein (XAC2156) and Ferritin-like di-iron-carboxylate protein (XAC2155) were upregulated by DSF/Rpf -mediated QS and possibly involved in the
Table 5 Summary of Xac DEGs encoding hypothetical proteins regulated by DSF/Rpf-mediated QS during pathogenic process

\begin{tabular}{|c|c|c|c|}
\hline Locus tag & $\begin{array}{l}\text { Log }_{2} \text { Fold } \\
\text { Change } \\
\text { (Wt/DrpfF) }\end{array}$ & Homologue [Bacterial species] & Identity $(\%)^{c}$ \\
\hline XAC2155 & 1.36 & $\begin{array}{l}\text { ferritin-like domain-containing } \\
\text { protein [Xanthomonas group] }\end{array}$ & 99 \\
\hline XAC2156 & 1.97 & stress-induced protein [X. phaseoli] & 98 \\
\hline XAC3073 & 1.01 & $\begin{array}{l}\text { GH18_chitinase-like glycosyl } \\
\text { hydrolase }[X . \text { citri }]\end{array}$ & 99 \\
\hline XAC3533 & 1.23 & $\begin{array}{l}\text { glycosyltransferase, GT2 family } \\
\text { [X. axonopodis] }\end{array}$ & 97 \\
\hline XAC3546 & 1.29 & $\begin{array}{l}\text { autotransporter adhesion protein } \\
\text { [X.citri] }\end{array}$ & 99 \\
\hline XAC0295 & -1.64 & 5-hydroxyisourate hydrolase [X. citri] & 98 \\
\hline XAC0297 & -2.93 & $\begin{array}{l}\text { 2-oxo-4-hydroxy-4-carboxy-5- } \\
\text { ureidoimidazoline decarboxylase } \\
\text { [X. citri] }\end{array}$ & 99 \\
\hline XAC0298 & -1.84 & $\begin{array}{l}\text { Nuclear transport factor } 2 \text { (NTF2- } \\
\text { like) superfamily [X. axonopodis] }\end{array}$ & 99 \\
\hline XAC0510 & -1.22 & $\begin{array}{l}\text { FUSC-like inner membrane protein } \\
\text { (fusaric acid resistance) }[X \text {. citri }]\end{array}$ & 98 \\
\hline XAC1397 & -2.05 & $\begin{array}{l}\text { Alginate export domain containing } \\
\text { protein }[X \text {. axonopodis }]\end{array}$ & 99 \\
\hline XAC1471 & -1.12 & $\begin{array}{l}\text { Glycine zipper 2TM domain } \\
\text { containing protein [X. citri] }\end{array}$ & 98 \\
\hline XAC1827 & -2.41 & $\begin{array}{l}\text { Trp repressor protein [Xanthomonas } \\
\text { group] }\end{array}$ & 99 \\
\hline XAC1883 & -1.00 & $\begin{array}{l}\text { AbrB domain containing } \\
\text { transcriptional regulator }[X \text {. citri }]\end{array}$ & 99 \\
\hline XAC1884 & -1.26 & $\begin{array}{l}\text { PIN (PilT N terminus) domain- } \\
\text { containing protein }[X . \text { citri }]\end{array}$ & 99 \\
\hline XAC2821 & -1.02 & $\begin{array}{l}\text { Crotonase/Enoyl-Coenzyme A (CoA) } \\
\text { hydratase [Xanthomonas group] }\end{array}$ & 99 \\
\hline XAC2934 & -1.02 & $\begin{array}{l}\text { Fe-S assembly SUF system } \\
\text { transcriptional regulator }[X \text {. citri }]\end{array}$ & 99 \\
\hline XAC3085 & -1.06 & $\begin{array}{l}\text { putative type III secretion system } \\
\text { effector protein [Xanthomonas } \\
\text { group] }\end{array}$ & 99 \\
\hline XAC3439 & -1.16 & $\begin{array}{l}\text { putative secreted protein } \\
\text { [Xanthomonas group] }\end{array}$ & 99 \\
\hline XAC3506 & -1.67 & $\begin{array}{l}\text { Cellulose belonging to glycosyl } \\
\text { hydrolase family } 5[X \text {. citri }]\end{array}$ & 98 \\
\hline XAC3507 & -1.99 & $\begin{array}{l}\text { CelS cellulose; Glycosyl hydrolase } \\
12 \text { superfamily [Xanthomonas } \\
\text { group] }\end{array}$ & 98 \\
\hline XAC3720 & -1.17 & $\begin{array}{l}\text { putative two-component system } \\
\text { sensor kinase [Xanthomonas group] }\end{array}$ & 99 \\
\hline XAC3753 & -1.22 & $\begin{array}{l}\text { putative chemotaxis membrane } \\
\text { protein [Xanthomonas group] }\end{array}$ & 99 \\
\hline XAC3754 & -1.01 & $\begin{array}{l}\text { putative chemotaxis membrane } \\
\text { protein [Xanthomonas group] }\end{array}$ & 99 \\
\hline XAC3856 & -1.19 & $\begin{array}{l}\text { calcium-binding protein, EFh } \\
\text { Superfamily [X. citri] }\end{array}$ & 99 \\
\hline XAC4219 & -1.09 & $\begin{array}{l}\text { Lipid-binding SYLF domain } \\
\text { containing protein [Xanthomonas } \\
\text { group] }\end{array}$ & 99 \\
\hline
\end{tabular}


adaptation of Xac to the host environment. The genes encoding putative GH18_chitinase-like glycosyl hydrolase (XAC3073) and GT2 family glycosyltransferase (XAC3533) were also upregulated, involved in carbohydrate transport and metabolism. In contrast, the gene XAC3085 encoding a putative T3SS effector protein was downregulated, with an unknown function in Xac-citrus interaction.

\section{Comparison of the DSF/Rpf-mediated QS regulons in planta and in vitro}

Our previous work identified 180 genes constituting the DSF/RpfF regulon of $\mathrm{Xac}$ grown in culture medium in the exponential and/or stationary growth phase [17]. Among those, a set of 31 genes were overlapping with the in planta DSF/Rpf regulon, 26 of which showed similar trends in alteration of expression between the two environmental conditions (Additional file 5: Table S5). Specifically, a subset of 20 genes were identified in the $\mathrm{DSF} / \mathrm{RpfF}$ regulon of $\mathrm{Xac}$ in the exponential growth phase, 25 genes were identified in the DSF/RpfF regulon of Xac in the stationary growth phase, and 14 genes were identified in both regulons. These genes were primarily involved in energy metabolism (carbohydrate transport and metabolism), protein fate and protein synthesis (amino acid transport and metabolism or post-translational modification), and signal transduction or transcriptional regulation, and some encode hypothetical proteins with unknown functions.

\section{Overview of citrus transcriptional responses to DSF/Rpf- mediated Xac infection}

Global analyses of the citrus transcripts in response to DSF/Rpf-mediated Xac infection revealed that the protein families related to stress responses, signaling pathways, hormone metabolism, and cell wall modification were over-represented according to the gene ontology (GO) analysis (Fig. 4). Individual gene responses in metabolic pathways were visualized using the MapMan tool (Fig. 5). Remarkable downregulation was observed for many genes related to photosynthesis, secondary metabolism, and plant defense response.

\section{DSF/Rpf -mediated Xac infection represses photosynthesis} in citrus

The expression levels of nine genes involved in photosynthesis decreased significantly in wild type Xac strain 306 infected leaf tissues, compared with the $\triangle r p f F$ mutant infected leaf tissues (Table 6). Transcripts for photosystem II oxygen-evolving enhancer protein PsbO (Cs7g03508) and photosystem II $22 \mathrm{kDa}$ protein PsbS (Cs3g19650) were less abundant in wild type Xac infected leaves. Three transcripts encoding subunits of photosystem I also decreased in wild type $\mathrm{Xac}$ infected leaves, including photosystem I reaction center subunit II (PsaD), VI-2 (PsaH), and $\mathrm{O}$ subunit (PsaO). In addition, the genes for photosynthetic electron transport protein plastocyanin (PetE) and for an ATP synthase subunit (the F-type $\mathrm{H}+$-transporting ATPase subunit gamma, Cs4g10260) were downregulated in wild type Xac infected leaves (Table 6). These results are in agreement with the notion that $X a c$ is biotrophic during early stages of host infection [48, 49] and that biotrophic pathogen infection generally represses photosynthesis in host plants [50].

\section{Alterations of hormone metabolisms in citrus responding to DSF/Rpf-mediated Xac infection}

Significant transcriptional changes in response to DSF/ Rpf-mediated Xac infection were observed for a group of genes related to plant hormone biosynthesis, transportation, metabolism, and associated signal transduction (Table 7). Transcripts for auxin biosynthesis-related enzymes and auxin-responsive proteins, including indole-3-acetate beta-D-glucosyltransferase (IAGLU), UDP-glucosyltransferase (UGT74E2), and SAUR (small auxin-up RNA) -like auxin-responsive protein, were more abundant, while genes for the PIN or PIN-LIKES class of auxin transporters were downregulated in wild type Xac infected leaves. The gene Cs2g03270 encoding a 9-cis-epoxycarotenoid dioxygenase, a key enzyme for abscisic acid (ABA) biosynthesis [51], was downregulated in wild type Xac infected leaves, and gens for ABA-responsive (ABR) proteins were upregulated in wild type Xac infected leaves. Three genes involved in cytokinin biosynthesis (cytokinin synthase, isopentenyltransferase (IPT), and UDP-Glycosyltransferase superfamily protein) were downregulated in wild type $\mathrm{Xac}$ infected leaves, while two genes involved in cytokinin metabolic process (UDP-glucosyl transferase 85A5 (UGT85A5) and DON-Glucosyltransferase) were upregulated in wild type $\mathrm{Xac}$ infected leaves.

A total of 17 genes encoding the ethylene response factor (ERF) transcription factors were differentially expressed in wild type Xac infected leaves compared to $\Delta r p f F$ mutant infected leaves (Table 7). In particular, the transcripts for ERF1 and RAP2.1 were more abundant in wild type $X a c$ infected leaves, while transcripts for EREBP-3, ERF-4, ERF-6, ERF104, and for an ethyleneregulated nuclear protein (ERT2) were less abundant in wild type Xac infected leaves. One gene (Cs4g05190) involved in ethylene biosynthesis was upregulated in wild type Xac infected leaves. Two genes for gibberellic acid (GA) biosynthesis (the CYP701A cytochrome p450 family protein) and GA inactivation (GA2OX: gibberellin 2-oxidase) [52] were downregulated in wild type $\mathrm{Xac}$ infected leaves (Table 7). Three genes involved in the GA response were also downregulated in wild type $\mathrm{Xac}$ 

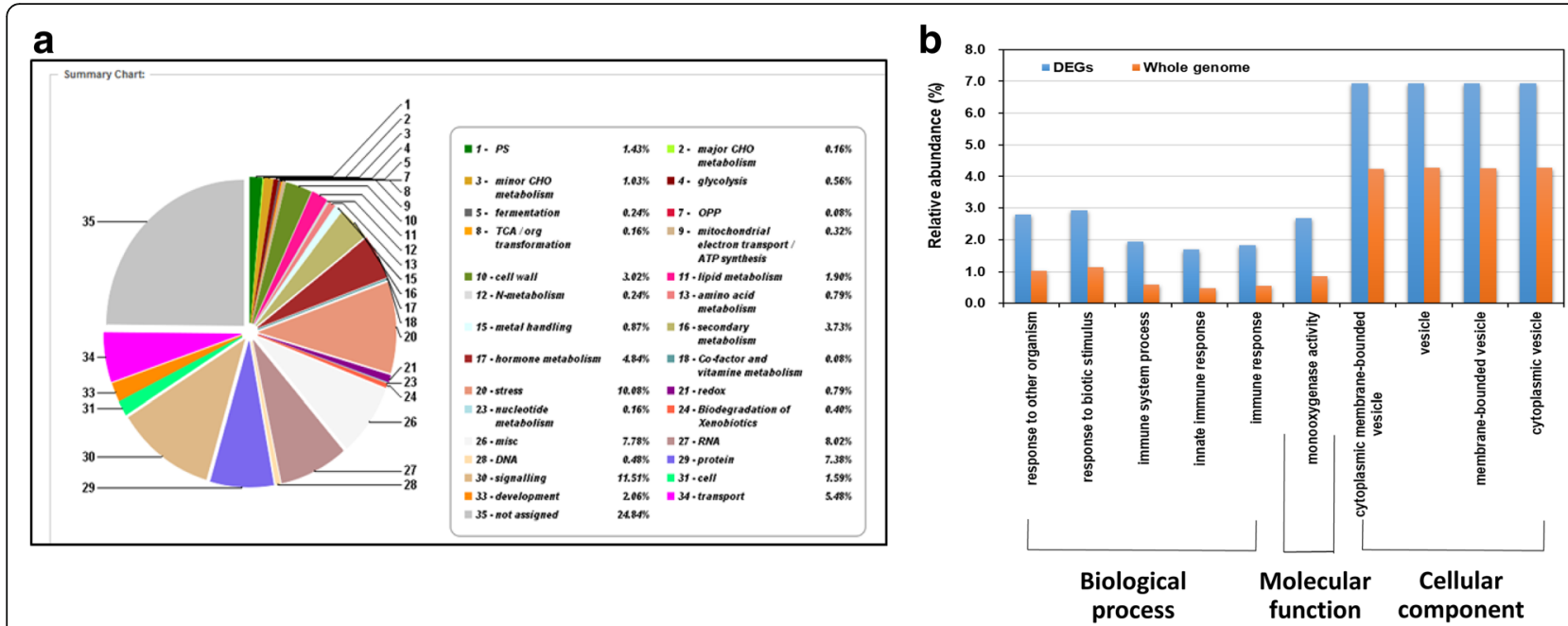

Fig. 4 Gene Ontology classification of citrus differentially expressed genes (DEGs) response to the DSF/Rpf-mediated Xanthomonas citri subsp. citri infection. a Pie diagram depicting the relative abundance of each category of DEGs. The category was presented by functional classification followed by the corresponding percentage. b Column chart showing the relative abundance of the three main categories of DEGs: biological process, cellular component, and molecular function

infected leaves, including those GAST-like (gibberellic acid stimulated transcript-like) and ARM repeat superfamily proteins.

Three genes involved in jasmonic acid (JA) biosynthesis or metabolisms were upregulated in wild type Xac infected leaves compared to $\triangle r p f F$ mutant infected leaves (Table 7). These included the gene encoding 12-oxophytodienoic acid reductases (OPR) (orange1.1 t03726) and the gene encoding a FMN-containing oxidoreductases (orange1.1 t03729) (for JA biosynthesis), and a S-adenosyl-L-methionine:jasmonic acid carboxyl methyltransferase (JMT) that catalyzes the formation of

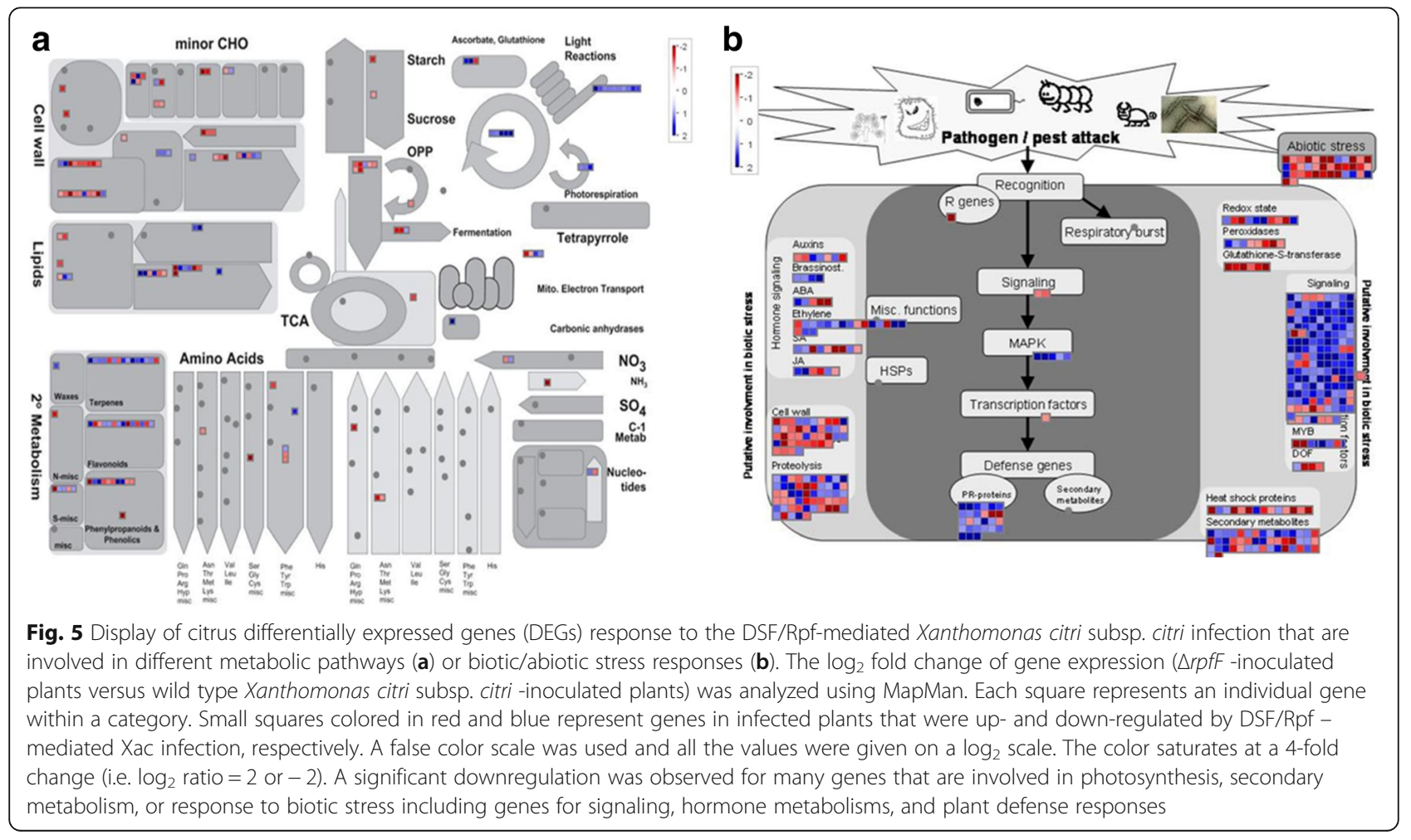


Table 6 Summary of citrus DEGs genes involved in photosynthesis

\begin{tabular}{|c|c|c|c|}
\hline $\mathrm{ID}$ & Gene name (Locus) & $\begin{array}{l}\text { Log }_{2} \text { Fold } \\
\text { Change } \\
\text { (Wt/Drpff) }\end{array}$ & $\begin{array}{l}\text { Annotation/ Protein } \\
\text { function }\end{array}$ \\
\hline XLOC_017330 & psbQ (Cs7g03580) & -1.36 & $\begin{array}{l}\text { photosystem II } \\
\text { oxygen-evolving } \\
\text { enhancer protein }\end{array}$ \\
\hline XLOC_008489 & psbS (Cs3g19650) & -2.10 & $\begin{array}{l}\text { photosystem II } 22 \\
\text { kDa protein }\end{array}$ \\
\hline XLOC_014472 & psaD (Cs5g31180) & -1.18 & $\begin{array}{l}\text { photosystem I } \\
\text { reaction center } \\
\text { subunit II }\end{array}$ \\
\hline XLOC_002098 & psaH (Cs1g15170) & -1.14 & $\begin{array}{l}\text { photosystem I } \\
\text { reaction center } \\
\text { subunit VI-2 }\end{array}$ \\
\hline XLOC_015536 & psaO (Cs6g12390) & -1.13 & $\begin{array}{l}\text { photosystem I } \\
\text { subunit } O\end{array}$ \\
\hline XLOC_008847 & petE (Cs3g26730) & -1.22 & $\begin{array}{l}\text { photosynthetic } \\
\text { electron transport } \\
\text { protein plastocyanin }\end{array}$ \\
\hline XLOC_004226 & Cs2g26640 & -1.27 & $\begin{array}{l}\text { GLK2 transcription } \\
\text { factor, regulating } \\
\text { the expression of } \\
\text { photosynthetic } \\
\text { apparatus }\end{array}$ \\
\hline XLOC_010577 & atpA (Cs4g10260) & -1.07 & $\begin{array}{l}\text { F-type } \mathrm{H}+ \\
\text {-transporting ATPase } \\
\text { subunit gamma }\end{array}$ \\
\hline XLOC_001762 & psan (Cs1g09130) & 1.23 & $\begin{array}{l}\text { photosystem I reaction } \\
\text { center subunit } \mathrm{N}\end{array}$ \\
\hline
\end{tabular}

methyl jasmonate (MeJA) from JA (Cs7g31430) [53]. In contrast, two genes (orange1.1 t03773 and orange1.1 t04376) encoding the chloroplast lipoxygenases required for wound-induced JA accumulation in Arabidopsis were downregulated in wild type Xac infected leaves. Three genes involved in SA metabolisms were differentially expressed in wild type Xac infected leaves compared to $\triangle r p f F$ mutant infected leaves (Table 7). Notably, a gene (Cs1g23160) encoding the methyl esterase 1 (MES1) with methyl salicylate (MeSA) esterase activity of hydrolyzing MeSA to SA in planta [54], was upregulated in wild type $X a c$ infected leaves. In addition, two genes (Cs2g28310 and Cs6g18050) encoding S-adenosyl-Lmethionine-dependent methyl transferases superfamily proteins involved in SA metabolic process were downregulated in wild type Xac infected leaves. Furthermore, four genes involved in brassinosteroid (BR) biosynthesis or responses were repressed in wild type Xac infected leaves. They are a cycloartenol synthase 1 (CAS1) and a C-8 sterol isomerase involved in the biosynthesis of BR, and two leucine-rich receptor-like protein kinase family proteins involved in BR signaling pathways [55] (Table 7).

\section{Citrus defense responses to DSF/Rpf-mediated Xac infection}

Of the 1946 citrus DEGs between wild type Xac infected - and $\Delta r p f F$ mutant infected - libraries, 102 genes (5.4\%) were identified to be involved in plant defense responses, with 32 genes upregulated and 70 genes downregulated by DSF/Rpf-mediated Xac infection (Additional file 6: Table S6; Table 8). Remarkably, 34 genes encoding plant immune receptor-like proteins or receptor-like kinases were downregulated. Eight genes encoding transcription regulators were downregulated, including three WRKY transcription factors- encoding genes (one for WRKY 4 and two for WRKY 53). In addition, four genes encoding pathogenesis-related (PR) family proteins were downregulated, including the genes encoding members of the PR-5 (thaumatin) and PR-6 (protease inhibitor) subfamily (Additional file 6: Table S6). Three Kunitz protease inhibitors encoding genes were also downregulated, which were suggested to modulate programmed cell death in in Arabidopsis during plant-pathogen interactions [56]. Other downregulated genes included five genes encoding NB-ARC (nucleotide-binding adaptor shared by Apaf- 1 , resistance proteins, and CED-4) domain-containing disease resistance proteins [57], and three genes encoding MYB transcription factor family proteins, which are involved in various plant biological processes including defense responses [58].

Among the 32 genes upregulated by DSF/Rpf-mediated Xac infection, three genes encode WRKY transcription factors, including WRKY18, WRKY22, and WRKY54 (Table 8). Interestingly, in Arabidopsis, AtWRKY18 alone with AtWRKY40 and AtWRKY60, act as negative regulators of defense signaling [59]. Other upregulated genes include two genes coding for the MYB transcription factors, three genes for the PR family proteins including one PR-5 and two PR- 6 , four genes for the NB-LRR family receptors, five genes for wound-responsive or -induced proteins, and a few others for disease resistance responsive proteins and stress responsive proteins (Additional file 6: Table S6).

\section{Expression of citrus genes associated with plant secondary metabolism and cell wall modification were altered by DSF/Rpf-mediated Xac infection}

A total of 14 citrus genes related to the biosynthesis of flavonols, anthocyaninins, glucosinolates and terpenoids, which are well characterized defensive compounds [60], were downregulated by DSF/Rpf-mediated Xac infection (Additional file 7: Table S7). Five genes involved in lignin biosynthesis were upregulated by DSF/Rpf-mediated Xac infection, suggesting that lignin might be deposited in infected tissues, possibly as part of citrus responses to limit the pathogen colonization. Indeed, $X a c$ infection induced the expression of genes 
Table 7 Summary of citrus DEGs genes involved in plant hormone metabolisms

\begin{tabular}{|c|c|c|c|}
\hline ID & Locus & 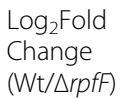 & Annotation/ Protein function \\
\hline
\end{tabular}

Auxin biosynthesis, metabolism, and signaling

$\begin{array}{lll}\text { XLOC_012174 } & \text { Cs5g20410 } & 1.22 \\ \text { XLOC_031022 } & - & 1.38 \\ \text { XLOC_005577 } & \text { Cs2g23750 } & 2.45 \\ & & \\ & & \\ \text { XLOC_029081 } & \text { orange1.1 } & 1.65 \\ & \text { t02620 } & \\ \text { XLOC_003150 } & \text { Cs2g06290 } & 1.00 \\ & & \\ \text { XLOC_015754 } & \text { Cs6g17000 } & -1.61 \\ \text { XLOC_020295 } & \text { Cs7g31320 } & -1.19 \\ & & \\ \text { XLOC_008042 } & \text { Cs3g10670 } & -1.28\end{array}$

Abscisic acid (ABA) -related genes

$\begin{array}{lll}\text { XLOC_004564 Cs2g03270 } & -1.21 \\ \text { XLOC_004925 Cs2g10990 } & -1.71 \\ \text { XLOC_017286 Cs7g02850 } & 2.07 \\ & & \\ \text { XLOC_017832 } & \text { Cs7g13470 } & 2.64 \\ & & \\ \text { XLOC_012807 Cs5g32930 } & 1.29\end{array}$

Ethylene - related genes

\begin{tabular}{|c|c|c|c|}
\hline XLOC_010327 & Cs4g05190 & 1.48 & $\begin{array}{l}\text { flavanone } 3 \text { hydroxylase, } \\
\text { 2-oxoglutarate ( } 20 \mathrm{OG} \text { ) and } \\
\text { Fe(II)-dependent oxygenase } \\
\text { superfamily protein, involved } \\
\text { in ethylene synthesis }\end{array}$ \\
\hline XLOC_004668 & Cs2g05280 & 1.08 & $\begin{array}{l}\text { ERF (ethylene response } \\
\text { factor) subfamily B-3 of } \\
\text { ERF/AP2 transcription } \\
\text { factor family (ERF1) }\end{array}$ \\
\hline XLOC_014405 & Cs5g29870 & 1.86 & $\begin{array}{l}\text { ERF (ethylene response } \\
\text { factor) subfamily B-3 of } \\
\text { ERF/AP2 transcription factor } \\
\text { family (ERF1) }\end{array}$ \\
\hline XLOC_024633 & - & 1.36 & $\begin{array}{l}\text { ERF (ethylene response } \\
\text { factor) subfamily B-3 of }\end{array}$ \\
\hline
\end{tabular}

Table 7 Summary of citrus DEGs genes involved in plant hormone metabolisms (Continued)

\begin{tabular}{|c|c|c|c|}
\hline $\mathrm{ID}$ & Locus & 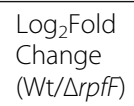 & Annotation/ Protein function \\
\hline & & & $\begin{array}{l}\text { ERF/AP2 transcription factor } \\
\text { family(ERF1) }\end{array}$ \\
\hline XLOC_007284 & Cs3g23270 & 1.79 & $\begin{array}{l}\text { DREB subfamily A-5 of } \\
\text { ERF/AP2 transcription } \\
\text { factor family (RAP2.1) }\end{array}$ \\
\hline XLOC_005573 & Cs2g23660 & -1.31 & $\begin{array}{l}\text { Ethylene-responsive } \\
\text { transcription factor } 4 \\
\text { (Ethylene-responsive } \\
\text { element-binding factor } \\
4 \text { homolog) (EREBP-3) }\end{array}$ \\
\hline XLOC_003119 & Cs2g05620 & -1.32 & $\begin{array}{l}\text { Ethylene-responsive } \\
\text { transcription factor } 4 \\
\text { (Ethylene-responsive } \\
\text { element-binding factor } \\
4 \text { homolog) (EREBP-3) }\end{array}$ \\
\hline XLOC_001696 & Cs1g07950 & -1.17 & $\begin{array}{l}\text { ERF (ethylene response } \\
\text { factor) subfamily B-1 of } \\
\text { ERF/AP2 transcription } \\
\text { factor family (ERF-4) }\end{array}$ \\
\hline XLOC_001450 & Cs1g03280 & -1.07 & $\begin{array}{l}\text { ERF (ethylene response } \\
\text { factor) subfamily B-3 of } \\
\text { ERF/AP2 transcription } \\
\text { factor family (ERF13) }\end{array}$ \\
\hline XLOC_014725 & - & -2.28 & $\begin{array}{l}\text { ERF (ethylene response } \\
\text { factor) subfamily B-3 of } \\
\text { ERF/AP2 transcription factor } \\
\text { family (ERF-6) }\end{array}$ \\
\hline XLOC_024283 & Cs9g13620 & -2.24 & $\begin{array}{l}\text { ERF (ethylene response } \\
\text { factor) subfamily B-3 of } \\
\text { ERF/AP2 transcription factor } \\
\text { family (ERF104) }\end{array}$ \\
\hline XLOC_023353 & Cs9g13610 & -2.04 & $\begin{array}{l}\text { ERF (ethylene response } \\
\text { factor) subfamily B-3 of } \\
\text { ERF/AP2 transcription } \\
\text { factor family (ERF104) }\end{array}$ \\
\hline XLOC_003353 & Cs2g09980 & -1.39 & $\begin{array}{l}\text { Ethylene-responsive nuclear } \\
\text { protein / ethylene-regulated } \\
\text { nuclear protein (ERT2) }\end{array}$ \\
\hline XLOC_028605 & $\begin{array}{l}\text { orange } 1.1 \\
\text { t01663 }\end{array}$ & -1.38 & $\begin{array}{l}\text { Adenine nucleotide alpha } \\
\text { hydrolases-like superfamily } \\
\text { protein, involved in response } \\
\text { to stress }\end{array}$ \\
\hline XLOC_002875 & Cs2g01100 & -1.97 & $\begin{array}{l}\text { DUF247 domain containing } \\
\text { plant protein, probably } \\
\text { involved in ethylene signal } \\
\text { transduction }\end{array}$ \\
\hline XLOC_004471 & Cs2g01150 & -1.43 & $\begin{array}{l}\text { DUF247 domain containing } \\
\text { plant protein, probably } \\
\text { involved in ethylene signal } \\
\text { transduction }\end{array}$ \\
\hline XLOC_004467 & Cs2g01090 & -1.01 & $\begin{array}{l}\text { DUF247 domain containing } \\
\text { plant protein, probably } \\
\text { involved in ethylene signal } \\
\text { transduction }\end{array}$ \\
\hline XLOC_014014 & Cs5g22160 & -1.18 & $\begin{array}{l}\text { DUF247 domain containing } \\
\text { plant protein, probably } \\
\text { involved in ethylene signal }\end{array}$ \\
\hline
\end{tabular}


Table 7 Summary of citrus DEGs genes involved in plant hormone metabolisms (Continued)

\begin{tabular}{ll}
\hline ID Locus & Log $_{2}$ Fold Annotation/ Protein function \\
& Change \\
& $($ Wt/ $/ \Delta$ rpf $)$ \\
\hline
\end{tabular}

transduction

Cytokinin - related genes

\begin{tabular}{|c|c|c|c|}
\hline XLOC_023917 & Cs9g06010 & -1.51 & $\begin{array}{l}\text { cytokinin synthase for } \\
\text { cytokinin biosynthesis }\end{array}$ \\
\hline XLOC_003491 & Cs2g12620 & -1.14 & $\begin{array}{l}\text { putative adenylate } \\
\text { isopentenyltransferase (IPT), } \\
\text { involved in cytokinin } \\
\text { biosynthesis }\end{array}$ \\
\hline XLOC_008154 & Cs3g12960 & -1.59 & $\begin{array}{l}\text { UDP-Glycosyltransferase } \\
\text { superfamily protein, } \\
\text { involved in cytokinin } \\
\text { biosynthesis }\end{array}$ \\
\hline XLOC_030591 & $\begin{array}{l}\text { orange } 1.1 \\
\text { t05518 }\end{array}$ & 1.01 & $\begin{array}{l}\text { UDP-glucosyl transferase } \\
85 \text { A5 (UGT85A5), involved } \\
\text { in cytokinin metabolic } \\
\text { process }\end{array}$ \\
\hline XLOC_030963 & - & 1.47 & $\begin{array}{l}\text { DON-Glucosyltransferase, } \\
\text { UDP-Glucosyl transferase } \\
\text { superfamily protein, } \\
\text { involved in cytokinin } \\
\text { metabolic process }\end{array}$ \\
\hline
\end{tabular}

Gibberellic acid (GA)- related genes

\begin{tabular}{|c|c|c|c|}
\hline XLOC_019477 & Cs7g14940 & -1.17 & $\begin{array}{l}\text { gibberellin 2-oxidase } \\
\text { (GA2OX), involved in } \\
\text { gibberellin metabolic } \\
\text { process }\end{array}$ \\
\hline XLOC_028715 & $\begin{array}{l}\text { orange } 1.1 \\
\text { t01909 }\end{array}$ & -1.81 & $\begin{array}{l}\text { CYP701A cytochrome } \\
\text { p450 family protein, } \\
\text { involved in gibberellin } \\
\text { biosynthesis }\end{array}$ \\
\hline XLOC_005279 & Cs2g17800 & -1.57 & $\begin{array}{l}\text { ARM (Armadillo-type fold) } \\
\text { repeat superfamily protein, } \\
\text { involved in GA signal } \\
\text { transduction }\end{array}$ \\
\hline XLOC_005280 & Cs2g17820 & -1.14 & $\begin{array}{l}\text { ARM (Armadillo-type fold) } \\
\text { repeat superfamily protein, } \\
\text { involved in GAsignal } \\
\text { transduction }\end{array}$ \\
\hline XLOC_008817 & Cs3g26100 & -1.11 & $\begin{array}{l}\text { GA-responsive GAST like } \\
\text { protein }\end{array}$ \\
\hline XLOC_006493 & Cs3g07395 & 1.16 & $\begin{array}{l}\text { Gibberellin-regulated family } \\
\text { protein }\end{array}$ \\
\hline \multicolumn{4}{|c|}{ Salicylic acid (SA) - related genes } \\
\hline XLOC_001130 & Cs1g23160 & 1.00 & $\begin{array}{l}\text { Methyl salicylate (MeSA) } \\
\text { esterase-like protein, } \\
\text { involved in MeSA } \\
\text { hydrolysis to SA }\end{array}$ \\
\hline XLOC_005805 & Cs2g28310 & -1.04 & $\begin{array}{l}\text { S-adenosyl-L-methionine- } \\
\text { dependent } \\
\text { methyltransferases } \\
\text { superfamily protein, } \\
\text { involved in SA metabolic } \\
\text { process }\end{array}$ \\
\hline XLOC_016863 & Cs6g18050 & -1.33 & $\begin{array}{l}\text { S-adenosyl-L-methionine- } \\
\text { dependent methyltransferases } \\
\text { superfamily protein, involved }\end{array}$ \\
\hline
\end{tabular}

Table 7 Summary of citrus DEGs genes involved in plant hormone metabolisms (Continued)

\begin{tabular}{lll}
\hline ID Locus & $\begin{array}{l}\text { Log }_{2} \text { Fold } \\
\text { Change } \\
\text { (Wt/Arpff })\end{array}$ \\
\hline & in SA metabolic process
\end{tabular}

Jasmonic acid (JA) - related genes

\begin{tabular}{|c|c|c|c|}
\hline XLOC_029628 & $\begin{array}{l}\text { orange } 1.1 \\
\text { t03726 }\end{array}$ & 1.35 & $\begin{array}{l}\text { 12-oxophytodienoic acid } \\
\text { reductases, involved in JA } \\
\text { biosynthesis }\end{array}$ \\
\hline XLOC_029630 & $\begin{array}{l}\text { orange } 1.1 \\
\text { t03729 }\end{array}$ & 1.64 & $\begin{array}{l}\text { FMN-containing oxidoreductases, } \\
\text { involved in JA biosynthesis }\end{array}$ \\
\hline XLOC_020298 & Cs7g31430 & 1.05 & $\begin{array}{l}\text { S-adenosyl-L-methionine: } \\
\text { jasmonic acid carboxyl } \\
\text { methyltransferase (JMT), } \\
\text { involved in JA metabolic } \\
\text { process to form } \\
\text { methyljasmonate (MeJA) }\end{array}$ \\
\hline XLOC_026677 & $\begin{array}{l}\text { orange } 1.1 \\
\text { t03773 }\end{array}$ & -1.51 & $\begin{array}{l}\text { Chloroplast lipoxygenase } \\
\text { required for wound-induced } \\
\text { JA accumulation in Arabidopsis }\end{array}$ \\
\hline XLOC_029950 & $\begin{array}{l}\text { orange } 1.1 \\
\text { t04376 }\end{array}$ & -2.04 & $\begin{array}{l}\text { Chloroplast lipoxygenase } \\
\text { required for wound-induced } \\
\text { JA accumulation in } \\
\text { Arabidopsis }\end{array}$ \\
\hline XLOC_002571 & Cs1g24440 & -1.22 & $\begin{array}{l}\text { S-adenosyl-L-methionine: } \\
\text { jasmonic acid carboxyl } \\
\text { methyltransferase (JMT), } \\
\text { involved in JA metabolic } \\
\text { process to form } \\
\text { methyljasmonate (MeJA) }\end{array}$ \\
\hline \multicolumn{4}{|c|}{ Brassinosteroid (BR) - related genes } \\
\hline XLOC_010301 & Cs4g04730 & -1.10 & $\begin{array}{l}\text { cycloartenol synthase } 1 \\
\text { (CAS1), involved in the } \\
\text { biosynthesis of BRs }\end{array}$ \\
\hline XLOC_012247 & Cs5g21830 & -1.12 & $\begin{array}{l}\text { C-8 sterol isomerase, } \\
\text { involved in the biosynthesis } \\
\text { of BRs }\end{array}$ \\
\hline XLOC_002765 & - & -2.43 & $\begin{array}{l}\text { Leucine-rich receptor-like } \\
\text { protein kinase family } \\
\text { protein, involved in BR } \\
\text { signaling pathways }\end{array}$ \\
\hline XLOC_006131 & - & -1.52 & $\begin{array}{l}\text { Leucine-rich receptor-like } \\
\text { protein kinase family } \\
\text { protein, involved in BR } \\
\text { signaling pathways }\end{array}$ \\
\hline
\end{tabular}

related to lignin biosynthesis [61]; and, histological analyses revealed an increased lignin deposition and the existence of cell wall reinforcement in $\mathrm{Xac}$ infected tissues [62]. Remarkably, 12 genes encoding cell-wallmodifying enzymes, including expansins, endoglucanases, glycosyl transferases, and xyloglucan endotransglycosylases/hydrolases, were upregulated by DSF/Rpf-mediated Xac infection (Additional file 8: Table S8). Nine genes encoding protein products involved in the synthesis of cell wall precursors were also upregulated. These results implied a more pronounced effect on cell wall modification upon 
Table 8 Summary of citrus DEGs genes encoding putative immune receptors and transcription factors involved in plant defense responses

\begin{tabular}{|c|c|c|c|}
\hline$\overline{\mathrm{ID}}$ & Locus & $\begin{array}{l}\text { Log }_{2} \text { Fold Chang) } \\
\text { (Wt/Arpff) }\end{array}$ & Annotation/ Protein function \\
\hline \multicolumn{4}{|c|}{ Receptor encoding genes } \\
\hline XLOC_030903 & - & -1.12 & Receptor like protein 1 (RLP1), Leucine-rich repeat-containing \\
\hline XLOC_028463 & orange1.1 t01371 & -1.36 & Receptor like protein 1 (RLP1), Leucine-rich repeat-containing \\
\hline XLOC_022248 & Cs8g14810 & -1.55 & Receptor like protein 1 (RLP1), Leucine-rich repeat-containing \\
\hline XLOC_007802 & Cs3g06050 & -1.99 & Receptor like protein 1 (RLP1), Leucine-rich repeat-containing \\
\hline XLOC_023272 & Cs9g12160 & -1.59 & Receptor like protein 13 (RLP13), Leucine-rich repeat-containing \\
\hline XLOC_023274 & Cs9g12220 & -2.09 & Receptor like protein 13 (RLP13), Leucine-rich repeat-containing \\
\hline XLOC_023264 & Cs9g12040 & -2.27 & Receptor like protein 13 (RLP13), Leucine-rich repeat-containing \\
\hline XLOC_006617 & Cs3g10050 & -2.30 & Receptor like protein 13 (RLP13), Leucine-rich repeat-containing \\
\hline XLOC_003292 & - & -2.30 & Receptor like protein 14 (RLP14), Leucine-rich repeat-containing \\
\hline XLOC_026146 & orange 1.1 t02820 & -1.15 & Receptor like protein 15 (RLP15), Leucine-rich repeat-containing \\
\hline XLOC_028464 & orange1.1 t01372 & -1.33 & Receptor like protein 15 (RLP15), Leucine-rich repeat-containing \\
\hline XLOC_025415 & orange1.1 t01415 & -1.66 & Receptor like protein 15 (RLP15), Leucine-rich repeat-containing \\
\hline XLOC_006615 & Cs3g10010 & -2.08 & Receptor like protein 15 (RLP15), Leucine-rich repeat-containing \\
\hline XLOC_015519 & Cs6g12110 & -2.13 & Receptor like protein 15 (RLP15), Leucine-rich repeat-containing \\
\hline XLOC_023261 & Cs9g11990 & -2.55 & Receptor like protein 15 (RLP15), Leucine-rich repeat-containing \\
\hline XLOC_030349 & orange1.1 t05075 & -1.31 & Receptor like protein 22 (RLP22), Leucine-rich repeat-containing \\
\hline XLOC_013590 & Cs5g13820 & -1.00 & Receptor like protein 33 (RLP33), Leucine-rich repeat-containing \\
\hline XLOC_005928 & Cs2g30850 & -1.63 & Receptor like protein 35 (RLP35), Leucine-rich repeat-containing \\
\hline XLOC_001914 & Cs1g11900 & -2.04 & Receptor like protein 54 (RLP54), Leucine-rich repeat-containing \\
\hline XLOC_030467 & orange1.1 t05273 & -1.52 & Receptor like protein 56 (RLP56), Leucine-rich repeat-containing \\
\hline XLOC_030282 & orange1.1 t04923 & -2.60 & Receptor like protein 56 (RLP56), Leucine-rich repeat-containing \\
\hline XLOC_030151 & orange1.1 t06047 & -1.12 & Receptor like protein 6 (RLP6), Leucine-rich repeat-containing \\
\hline XLOC_006431 & Cs3g06220 & -1.20 & Receptor like protein 6 (RLP6), Leucine-rich repeat-containing \\
\hline XLOC_005373 & Cs2g19490 & -1.17 & Receptor like protein 7 (RLP7), Leucine-rich repeat-containing \\
\hline XLOC_031340 & - & -2.93 & Receptor like protein 9 (RLP9), Leucine-rich repeat-containing \\
\hline XLOC_006131 & - & -1.52 & Receptor-like protein kinase family protein, Leucine-rich repeat-containing \\
\hline XLOC_012876 & Cs5g34310 & -1.09 & Receptor-like protein kinase family protein, Leucine-rich repeat-containing \\
\hline XLOC_015528 & Cs6g12270 & -2.24 & Receptor-like protein kinase family protein, Leucine-rich repeat-containing \\
\hline XLOC_002765 & - & -2.43 & Receptor-like protein kinase family protein, Leucine-rich repeat-containing \\
\hline XLOC_026533 & orange1.1 t03518 & -1.22 & Disease resistance protein (TIR-NBS-LRR class) with transmembrane receptor activity \\
\hline XLOC_029900 & orange1.1 t04292 & -1.30 & Disease resistance protein (TIR-NBS-LRR class) with transmembrane receptor activity \\
\hline XLOC_014032 & $\operatorname{Cs} 5 g 22400$ & -1.40 & Disease resistance protein (TIR-NBS-LRR class) with transmembrane receptor activity \\
\hline XLOC_006408 & Cs3g05870 & -1.14 & Disease resistance protein (CC-NBS-LRR class) family \\
\hline XLOC_006396 & Cs3g05690 & 1.99 & Disease resistance protein (TIR-NBS-LRR class) with transmembrane receptor activity \\
\hline XLOC_029612 & orange1.1 t03700 & 1.14 & Disease resistance protein (TIR-NBS-LRR class) with transmembrane receptor activity \\
\hline XLOC_006400 & Cs3g05760 & 1.09 & Disease resistance protein (TIR-NBS-LRR class) with transmembrane receptor activity \\
\hline XLOC_014130 & $\operatorname{Cs} 5 g 24240$ & 1.08 & Disease resistance protein (TIR-NBS-LRR class) with transmembrane receptor activity \\
\hline
\end{tabular}

Transcription factor encoding genes

$\begin{array}{lll}\text { XLOC_013026 } & \text { Cs5g03010 } & 1.08 \\ \text { XLOC_017469 } & \text { Cs7g06330 } & 1.17 \\ \text { XLOC_016450 } & \text { Cs6g10120 } & 1.19 \\ \text { XLOC_019872 } & \text { Cs7g23080 } & 1.46\end{array}$

WRKY transcription factor family protein (WRKY22)

WRKY transcription factor family protein (WRKY18)

WRKY transcription factor family protein (WRKY54)

MYB transcription factor family protein 
Table 8 Summary of citrus DEGs genes encoding putative immune receptors and transcription factors involved in plant defense responses (Continued)

\begin{tabular}{llll}
\hline ID & Locus & $\begin{array}{l}\text { Log } \text { Fold Chang) } \\
(\text { Wt/ArpfF) }\end{array}$ & Annotation/ Protein function \\
\hline XLOC_020617 & Cs8g02740 & 1.34 & MYB transcription factor family protein \\
XLOC_016421 & Cs6g09420 & -2.27 & WRKY transcription factor family protein (WRKY 4) \\
XLOC_028008 & orange1.1 t00472 & -1.26 & WRKY transcription factor family protein (WRKY53) \\
XLOC_013000 & Cs5g02450 & -1.04 & WRKY transcription factor family protein (WRKY53) \\
XLOC_005212 & Cs2g16510 & -2.28 & MYB transcription factor family protein \\
XLOC_014277 & Cs5g27440 & -1.82 & MYB transcription factor family protein \\
XLOC_024133 & Cs9g10480 & -1.54 & MYB transcription factor family protein \\
XLOC_011371 & Cs5g04290 & -1.52 & Homeobox transcription factor family protein \\
XLOC_013039 & Cs5g03250 & -1.29 & Homeobox transcription factor family protein \\
XLOC_021224 & Cs8g14700 & -1.66 & NAC domain transcription factor family protein \\
XLOC_021532 & Cs8g21030 & -1.08 & NAC domain transcription factor family protein \\
XLOC_025849 & orange1.1 t0226 & -1.32 & RNA-binding (RRM/RBD/RNP motifs) family protein \\
\hline
\end{tabular}

infection by the wild type Xac compared to the $\triangle r p f F$ mutant to limit the pathogen colonization.

\section{Discussion}

The in planta DSF/Rpf- mediated QS regulon of Xac

The results indicate that the DSF deficiency altered in planta expression of 202 genes in Xac, with a remarkable downregulation of different sets of genes functionally involved in stress tolerance, nutrition uptake and metabolisms, signal transduction, transcriptional regulation, and virulence. These findings support the hypothesis that the DSF/Rpf- mediated QS in Xac modulates diverse pathogenesis traits to promote bacterial adaptation to the host environment for a successful infection (Fig. 6). For example, Xac cells have to counteract environmental stresses and plant generated- oxidative stress during infection on citrus host [48, 63]. Our results showed that DSF/ Rpf-mediated QS contributes to stress tolerance of $X a c$ by positively regulating the expression of catalase, drug resistance translocase, defense protein-degrading endoproteinase, and the MFS drug transporter (Table 1). These enzymes are collectively important for bacterial resistance against diverse stresses from the environment and/or host organisms and thus for a successful infection [38, 64, 65]. DSF/Rpf-mediated QS also positively regulates the biosynthesis of trehalose, which protects Xac cells from osmotic and oxidative stresses to enable bacterial colonization in host plants [40], i.e., in the apoplast, an osmotic stressful environment [66].

The plant apoplast is low in nitrogen and rich in plant-derived sugars such as fructose [67]. Xac has adapted to the apoplast with diverse nutrient acquisition strategies evolved, including diverse enzymes for plant cell wall degradation, amino acid metabolism, carbohydrate metabolism and transportation [63]. The findings in this study indicate that Xac exploits the DSF/Rpf -mediated QS to regulate nutrition utilization during host infection (Table 2; Table 3). Interesting, the DSF/Rpf -mediated QS positively regulates the expression of phosphate transporter encoding genes, the homologues of which in $X$. axonopodis pv. glycines, the causal agent of bacterial pustule of soybean, have been demonstrated to be strongly expressed at early stages of infection and required for bacterial growth in host plants to promote disease [68]. DSF/Rpf-mediated QS also regulates ferric iron uptake of Xac in planta (Table 3). It has been reported that Xanthoferrin, a $\alpha$-hydroxycarboxylate-type siderophore produced by $X c c$ is required for its optimum virulence [69]; and, DSF positively regulates the functions involved in ferric iron uptake to promote in planta growth of $X$. oryzae pv. oryzicola [70]. However, there is no evidence that iron is limited or available to Xac cells grown in planta. The functional role of DSF/Rpf regulated ferric iron uptake in Xac biology and pathogenesis remains to be determined.

Importantly, the DSF/Rpf-mediated QS differentially regulated the expression of 12 determined or putative signal transducers and/or transcriptional regulators, most of which were downregulated, including the NtrB/C two-component system (Table 4). The NtrB/C system interacts with the $\mathrm{RpfC/G}$ system in responding to DSF signal to regulate sigma54-dependent promoters in Xac in vitro [44]. Our findings suggested that the DSF signal negatively regulates sigma54-dependent promoters through the RpfCG- NtrBCsigma54 pathway in Xac during early stages of host infection. The functional roles of the other signal transducers and/or transcriptional regulators regulated 


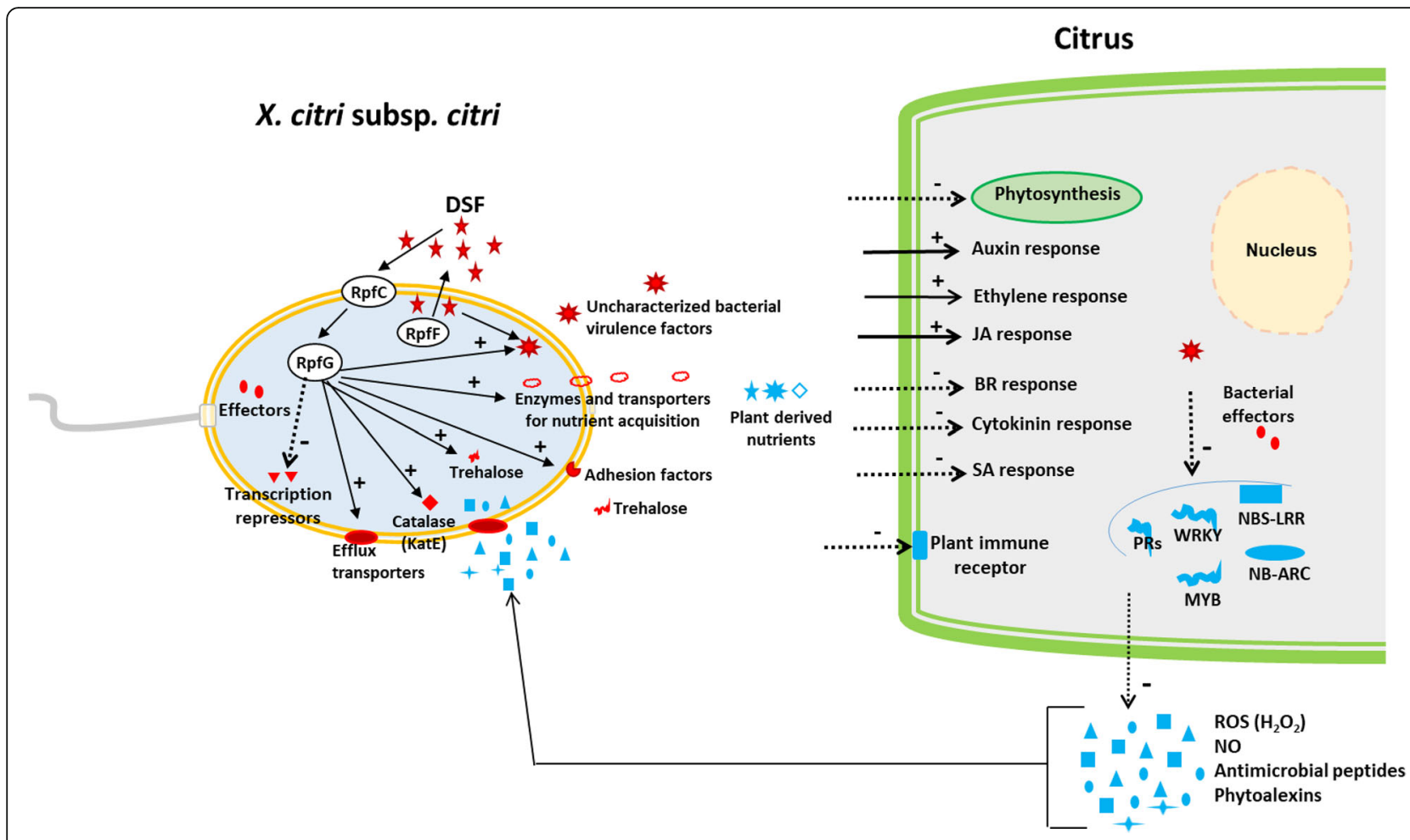

Fig. 6 Hypothetical model of the modulation of citrus - Xanthomonas citri subsp. citri interactions by the DSF/Rpf- mediated quorum sensing (QS) during early stages of infection. Representative proteins and metabolic processes with important roles in plant-pathogen interactions are shown. Plant and bacterial molecules are depicted in light blue and red, respectively. DSF/Rpf- mediated QS modulates expression of diverse bacterial traits including adhesion, nutrition acquisition, stress tolerance (catalase and trehalose), signal transduction, transcription, and virulence factors, which collectively promote bacterial adaptation to the host environment to favor infection. The transcriptional alterations of citrus in response to DSF-mediated $X$. citri subsp. citri infection are characterized by the downregulation of photosynthesis, plant immune receptor-like proteins or receptor-like kinases including NBS-LRRs, NB-ARC resistance proteins, MYB and WRKY transcription factors, and pathogenesis-related (PR) proteins. Changes of phytohormone metabolism and signaling were also triggered by DSF-mediated $X$. citri subsp. citri infection, probably leading to increased accumulation of auxin, ethylene and jasmonic acid (JA), and decreased accumulation of brassinosteroid (BR), cytokinin and salicylic acid (SA), which may benefit the pathogen. Solid arrows with plus symbols indicate positive regulation and dashed arrows with minus symbols indicate negative regulation. Solid lines indicate information flow

by the DSF/Rpf-mediated QS remain unknown. Collectively, the results suggested that DSF-mediated signaling might be linked with diverse regulators to enable complex patterns of gene expression to be employed by Xac to favor infection in host plants, which deserves further investigations.

Comparison of the in planta and in vitro DSF/RpfF regulons revealed that a set of 31 genes were commonly differentially regulated by DSF/RpfF under the two environment conditions. There are a large number of unique genes in the in planta regulon that were not regulated by DSF/RpfF in vitro (Additional file 5: Table S5). A couple of reasons could explain the differences among the in planta and in vitro DSF/RpfF regulons. It could be because of the difference in cell density of $\mathrm{Xac}$ in the two experimental conditions: approximately $10^{8} \mathrm{CFU} / \mathrm{cm}^{2}$ of leaf tissues for in planta experiments (Fig. 1b) and $10^{9}$ to $10^{10}$ $\mathrm{CFU} / \mathrm{ml}$ of growth medium for in vitro experiments
[17], as the QS regulates expression of genes in a cell density- dependent manner. It also could be because that the DSF/Rpf - mediated QS might play divers roles in regulating gene expression of $\mathrm{Xac}$ under different environment conditions. Several subsets of unique genes within the in planta regulon that were downregulated are involved in cell surface adhesion, stress tolerance, carbohydrate transport and metabolism, amino acids uptake and metabolism, signal transduction, and transcriptional regulation, which are in agreement with the findings produced in analysis of DSF/Rpf in vitro regulon [17]. The regulation pattern of Xac in planta compared to in vitro indicates the needs for real-time and in situ studies.

\section{Citrus transcriptional responses to DSF/Rpf-mediated Xac infection}

Gene expression data indicated that significant transcriptional alterations occurred in citrus plants in 
response to DSF/Rpf-mediated Xac infection, which caused various changes in plant immunity and physiology, thus favoring the pathogen infection. Especially, a large group of genes differentially expressed, related to plant hormone biosynthesis, transportation, metabolism, and associated signal transduction (Table 7). The results suggested the existence of elevated levels of auxin in wild type $X a c$ infected leaves compared with the $\triangle r p f F$ mutant infected leaves. Auxin has been shown to promote citrus canker development [71]; and auxin pathways play a role in tomato bacterial wilt caused by Ralstonia solanacearum [72]. Therefore, it is likely that the alterations in expression of auxin biosynthesis, mobilization and signaling genes in response to the DSF/Rpf-mediated Xac infection are associated with the citrus canker disease development. Additionally, cytokinin biosynthesis genes were downregulated and cytokinin metabolic genes were upregulated, implying decreased accumulation of cytokinin in wild type Xac infected leaves. Cytokinin has been shown to regulate plant defense responses in a dosage-dependent manner: strong activation of cytokinin signaling confers resistance to biotrophic pathogens via increased SA accumulation; by contrast, weak activation of cytokinin signaling suppresses pathogen-associated molecular pattern (PAMP)-triggered immunity (PTI) [73]. Our results suggested that the DSF/Rpf-mediated Xac infection modulates cytokinin accumulation and thus avoids strong activation of cytokinin signaling to promote host susceptibility. Another interesting finding is the upregulation of genes involved in the biosynthesis of and response to ethylene in wild type Xac infected leaves. Xac infection activates ethylene biosynthesis and signaling in citrus plants [61]. Ethylene is usually involved in plant defense responses against necrotrophic pathogens [74], thus it is possible that the successful establishment of Xac infection is favored by the development of inadequate plant defenses.

Notably, genes for JA biosynthesis and for SA production (i.e., the MeSA esterase) were upregulated in wild type $X a c$ infected leaves, while genes for SA metabolic process and for BR biosynthesis or responses were downregulated (Table 7). Earlier reports showed that certain antagonistic relationships occur between BR and JA, JA and SA pathways, and BR signaling negatively regulates plant defense against pathogens $[55,75,76]$. Both biotrophic and hemibitrophic pathogens employ the antagonism between JA and SA pathways and activate JA signaling to promote infection $[77,78]$. The findings in this study implied that the DSF/Rpf-mediated Xac infection may activate the JA signaling pathway and repress BR signaling to benefit the pathogen during early stages of infection.
Gene expression levels point to that the activity of DSF/Rpf-mediated QS might induce plant basal defenses and repress secondary defenses of citrus to promote Xac infection (Table 8; Additional file 6: Table S6; Additional file 7: Table S7; Additional file 8: Table S8). Remarkably, many plant immune receptor -like proteins or receptor-like kinases proteins were downregulated by DSF/Rpf-mediated Xac infection (Table 8), which are believed to perceive extracellular molecules, including microbe/pathogen-associated molecular patterns (M/PAMP) and environmental stimuli to induce plant basal resistance $[79,80]$. In addition, four putative NB-LRR family proteins were also downregulated by DSF/Rpf-mediated Xac infection, which are intracellular proteins and recognize pathogen effectors to lead to strong resistance responses [81]. Overall, it is important to note that more defense- related genes were downregulated than upregulated by DSF/Rpf-mediated Xac infection (70 downregulated versus 32 upregulated) (Additional file 6: Table S6), especially in the group of immune receptors (34 downregulated versus 4 upregulated) (Table 8).

It is not clear how the activity of DSF/Rpf-mediated QS triggers plant basal defenses and represses secondary defenses of citrus plants. One possible explanation might lie in the observations that the DSF signal molecule itself could elicit plant defense response in Xanthomonashost plant interactions and wild-type Xanthomonas spp. can suppress the DSF-induced defense responses by the production of the EPS xanthan and T3SS effectors [18]. Our results showed that the DSF/Rpf-mediated QS did not regulate or affect the production of the EPS xanthan by $X a c$ in citrus during early stages of infection, but negatively regulated the expression of a putative T3SS effector (XAC3085) (Table 5). The homologue of XAC3085 in X. campestris pv. vesicatoria (also termed $X$. euvesicatoria), the causal agent of bacterial spot disease on pepper and tomato, was determined as a T3SS effector named XopK, whose function remains unknown but seems not to contribute to the virulence of the pathogen [82]. Xac might suppress the DSF molecule elicited plant defense responses through the EPS and/or the T3SS effectors that are not affected by the DSF/ Rpf-mediated QS during host infection. Another possible reason might be the functional interplay between the bacterial T2SS and T3SS in modulating plant defense responses and promoting disease as observed in the $X$. oryzae pv. oryzae - rice interactions, where the bacterial T2SS secreted virulence factors: the ClsA cellulase and CbsA cellobiosidase, induced innate rice defense responses that were suppressed by T3S effectors [83]. We found that the DSF/Rpf-mediated QS positively regulates the expression of the homologue (engXCA/ XAC0612) of the ClsA cellulase (Table 2). Therefore, 
wild-type Xac may suppress, in a T3SS-dependent manner, the citrus plant defense responses probably induced by the T2SS effector cellulase (engXCA/XAC0612) to enable successful infection.

\section{Conclusions}

In conclusion, this work provides an in-depth transcriptomic analysis of DSF/Rpf -mediated QS regulation from both pathogen and host sides during the biotrophic interactions between $\mathrm{Xac}$ and citrus. Based on the results obtained, a model was presented that describes the major molecular and physiological aspects regulated by the DSF/Rpf- mediated QS during early stages of infection (Fig. 6). The findings support the hypothesis that the DSF/Rpf- mediated QS in Xac modulates diverse pathogenesis traits to promote bacterial adaptation to the host environment, and triggers various changes in plant immunity and physiology favoring the pathogen for successful infection. Taken together, the present work has provided novel insights into the role of the DSF/Rpf- mediated QS regulatory system in the pathogenic interactions between Xanthomonas and its host plants and expanded our current knowledge of DSFmediated QS regulation, and adds to our general understanding of plant-pathogen interactions.

\section{Additional Files}

Additional file 1: Table S1. Primers used for qRT-PCR assays for experimental validation (DOCX 18 kb)

Additional file 2: Table S2. Summary of the RNA-seq data (DOCX $13 \mathrm{~kb}$ ) Additional file 3: Table S3. Detail of the DEGs of Xanthomonas citri subsp. citri regulated by DSF/RpfF -mediated QS (DOCX $35 \mathrm{~kb}$ )

Additional file 4: Table S4. Detail of the DEGs of citrus in response to DSF/RpfF -mediated Xac infection (XLSX $183 \mathrm{~kb}$ )

Additional file 5: Table S5. Comparison of the in vitro and in planta DSF/Rpf-mediated QS regulons of Xanthomonas citri subsp. citri (XLSX 29 $\mathrm{kb})$

Additional file 6: Table S6. Differentially expressed citrus genes related to plant defense responses (XLSX $17 \mathrm{~kb}$ )

Additional file 7: Table S7. Differentially expressed citrus genes involved in plant secondary metabolisms (XLSX $11 \mathrm{~kb}$ )

Additional file 8: Table S8. Differentially expressed citrus genes involved in cell wall modifications (XLSX $13 \mathrm{~kb}$ )

\footnotetext{
Abbreviations

bp: Base pair; cDNA: Complementary DNA; COG: Clusters of Orthologous Groups; DEGs: Differentially expressed genes; DNA: Deoxyribonucleic acid: DSF: Diffusible signal factor; EPS: Extracellular polysaccharides; FDR: False rate discovery; FPKM: Fragments per kilobase of exon permillion mapped reads; kb: Kilobases; log2FC: Log of fold change in base 2; LPS: Lipopolysaccharides; min: Minute; mM: Millimolar; mRNA: Messenger RNA; PCR: Polymerase chain reaction; $\mathrm{pH}$ : Hydrogenionic potential; qRT-

PCR: Quantitative reverse transcription PCR; QS: Quorum sensing; RNA: Ribonucleic acid; RNA-Seq: RNA sequencing; Rpf: Regulation of pathogenicity factorsL; rpm: Rotations per minute; T2SS: Type II secretion system; T3SS: Type III secretion system; Xac: X. citri subsp. citri; Xcc: X. campestris pv. campestris; $\mu \mathrm{g}$ : Micrograms; $\mu \mathrm{M}$ : Micromolar
}

\section{Acknowledgments}

The authors would like to thank Zgiqian Pang and Doron Temper for insightful discussions.

\section{Funding}

This work was supported by Florida Citrus Research and Development Foundation and the US Department of Agriculture-National Institute of Food and Agriculture (USDA-NIFA) Plant Biotic Interactions Program 2017-6701326527 (to NW), and the China Scholarship Council (CSC) awarded (to LL).

\section{Availability of data and materials}

The RNA sequence dataset supporting the results in this article is available from the NCBI under the bioproject no. PRJNA421992 with the SRA accession no. SRP126698 (https://www.ncbi.nlm.nih.gov//sra/ ?term=SRP126698).

\section{Author's contributions}

NW, $J$, and $L L$ conceived and designed the experiments. $L L$ and $J L$ performed the experiments. $L L, J L, Y Z$, and NW analyzed data. $L L, J L, Y Z$, and NW wrote the manuscript. All authors read and approved the manuscript.

Ethics approval and consent to participate

Not applicable.

\section{Consent for publication}

Not applicable.

\section{Competing interests}

The authors declare that they have no competing interests.

\section{Publisher's Note}

Springer Nature remains neutral with regard to jurisdictional claims in published maps and institutional affiliations.

\section{Author details}

${ }^{1}$ Chinese Academy of Agricultural Sciences, Institute of Vegetables and Flowers, Beijing 100081, China. ${ }^{2}$ Citrus Research and Education Center, Department of Microbiology and Cell Science, University of Florida, Lake Alfred, FL 33850, USA.

Received: 14 April 2018 Accepted: 18 December 2018 Published online: 17 January 2019

\section{References}

1. Büttner D, Bonas U. Regulation and secretion of Xanthomonas virulence factors. FEMS Microbiol Rev. 2010;34:107-33.

2. Ryan RP, Vorhoelter FJ, Potnis N, Jones JB, Van Sluys MA, Bogdanove AJ, et al. Pathogenomics of Xanthomonas: understanding bacterium-plant interactions. Nat Rev Microbiol. 2011;9:344-55.

3. Strauß T, van Poecke RMP, Strauß A, Röme P, Minsavage GV, et al. RNA-seq pinpoints a Xanthomonas TAL-effector activated resistance gene in a largecrop genome. Proc Natl Acad Sci U S A. 2012;109(47):19480-5.

4. Zhou X, Hu X, Li J, Wang N. A novel periplasmic protein, VrpA, contributes to efficient protein secretion by the type III secretion system in Xanthomonas spp. Mol Plant-Microbe Interact. 2015;28(2):143-53.

5. Li J, Wang $N$. The gps $X$ gene encoding a glycosyltransferase is important for polysaccharide production and required for full virulence in Xanthomonas citri subsp. citri. BMC Microbiol. 2012;12:31.

6. Ryan RP, An SQ, Allan JH, McCarthy Y, Dow JM. The DSF-family of cell-cell signals: An expanding class of bacterial virulence regulators. PLoS Pathog. 2015;11:e1004986.

7. Dow JM. Diffusible signal factor-dependent quorum sensing in pathogenic bacteria and its exploitation for disease control. J Appl Microbiol. 2017; 122(1):2-11

8. Wang LH, He YW, Gao YF, Wu JE, Dong YH, He C, et al. A bacterial cell-cell communication signal with cross-kingdom structural analogues. Mol Microbiol. 2004;51:903-12.

9. Tang JL, Liu YN, Barber CE, Dow JM, Wootton JC, et al. Genetic and molecular analsysis of a cluster of rpf genes involved in positive regulation of synthesis of extracellular enzymes and polysaccharide in Xanthomonas campestris pathovar campestris. Mol Gen Genet. 1991;226:409-17. 
10. Slater H, Alvarez-Morales A, Barber CE, Daniels MJ. Dow JM. A twocomponent system involving an HD-GYP domain protein links cell-cell signalling to pathogenicity gene expression in Xanthomonas campestris. Mol Microbiol. 2000;38:986-1003.

11. Wang XY, Zhou L, Yang J, Ji GH, He YW. The RpfB-dependent quorum sensing signal turnover system is required for adaptation and virulence in rice bacterial blight pathogen Xanthomonas oryzae pv. oryzae. Mol PlantMicrobe Interact. 2016;29(3):220-30

12. Ryan RP, Fouhy Y, Lucey JF, Crossman LC, Spiro S, He YW, et al. Cell-cell signaling in Xanthomonas campestris involves an HD-GYP domain protein that functions in cyclic di-GMP turnover. Proc Natl Acad Sci U S A. 2006;103: 6712-7.

13. Ryan RP, McCarthy Y, Andrade M, Farah CS, Armitage JP, Dow JM. Cell-cell signal-dependent dynamic interactions between HD-GYP and GGDEF domain proteins mediate virulence in Xanthomonas campestris. Proc Natl Acad Sci U S A. 2010;107:5989-94.

14. Cai Z, Yuan ZH, Zhang H, Pan $Y$, Wu Y, Tian XQ, et al. Fatty acid DSF binds and allosterically activates histidine kinase RpfC of phytopathogenic bacterium Xanthomonas campestris pv. campestris to regulate quorumsensing and virulence. PLoS Pathog. 2017;13(4):e1006304.

15. Dow JM, Crossman L, Findlay K, He YQ, Feng JX, Tang JL. Biofilm dispersal in Xanthomonas campestris is controlled by cell-cell signaling and is required for full virulence to plants. Proc Natl Acad Sci U S A. 2003;100: 10995-00.

16. An SQ, Allan JH, McCarthy Y, Febrer M, Dow JM, et al. The PAS domaincontaining histidine kinase RpfS is a second sensor for the diffusible signal factor of Xanthomonas campestris. Mol Microbiol. 2014;92:586-97.

17. Guo Y, Zhang Y, Li JL, Wang N. Diffusible signal factor-mediated quorum sensing plays a central role in coordinating gene expression of Xanthomonas citri subsp citri. Mol Plant-Microbe Interact. 2012;25:165-79.

18. Kakkar A, Nizampatnam NR, Kondreddy A, Pradhan BB, Chatterjee S. Xanthomonas campestris cell-cell signaling molecule DSF (diffusible signal factor) elicits innate immunity in plants and is suppressed by the exopolysaccharide xanthan. J Exp Bot. 2015;66:6697-714.

19. Deng Y, Wu J, Yin W, Li P, Zhou J, Chen S, et al. Diffusible signal factor family signals provide a fitness advantage to Xanthomonas campestris pv. campestris in interspecies competition. Environ Microbiol. 2016;18: 1534-45.

20. He YW, Ng AY, Xu M, Lin K, Wang LH, Dong YH, Zhang LH. Xanthomonas campestris cell-cell communication involves a putative nucleotide receptor protein Clp and a hierarchical signalling network. Mol Microbiol. 2007;64: 281-92.

21. An SQ, Febrer M, McCarthy Y, Tang DJ, Clissold L, Kaithakottil G, et al. Highresolution transcriptional analysis of the regulatory influence of cell-to-cell signalling reveals novel genes that contribute to Xanthomonas phytopathogenesis. Mol Microbiol. 2013;88:1058-69.

22. O'Connell A, An SQ, McCarthy Y, Schulte F, Niehaus K, et al. Proteomics analysis of the regulatory role of Rpf/DSF cell-to-cell signaling system in the virulence of Xanthomonas campestris. Mol Plant-Microbe Interact. 2013;26: 1131-7.

23. Zhao Y, Qian G, Yin F, Fan J, Zhai Z, Liu C, Hu B, Liu F. Proteomic analysis of the regulatory function of DSF-dependent quorum sensing in Xanthomonas oryzae pv. oryzicola. Microb Pathogenesuis. 2011;50:48-55.

24. da Silva AC, Ferro JA, Reinach FC, Farah CS, Furlan LR, Quaggio RB, et al. Comparison of the genomes of two Xanthomonas pathogens with differing host specificities. Nature. 2002;417:459-63.

25. Langmead B, Salzberg SL. Fast gapped-read alignment with bowtie 2. Nat Methods. 2012;9:357-U54.

26. Love MI, Huber W, Anders S. Moderated estimation of fold change and dispersion for RNA-seq data with DESeq2. Genome Biol. 2014;15:550.

27. Trapnell C, Roberts A, Goff L, Pertea G, Kim D, et al. Differential gene and transcript expression analysis of RNA-seq experiments with TopHat and cufflinks. Nat Protoc. 2012;7(3):562-78.

28. Xu Q, Chen LL, Ruan X, Chen D, Zhu A, Chen C, et al. The draft genome of sweet orange (Citrus sinensis). Nat Genet. 2013;45:59-66.

29. Kim D, Pertea G, Trapnell C, Pimentel H, Kelley R, Salzberg SL. TopHat2: accurate alignment of transcriptomes in the presence of insertions, deletions and gene fusions. Genome Biol. 2013;14(4):R36.

30. Trapnell C, Hendrickson DG, Sauvageau M, Goff L, Rinn JL, Pachter L. Differential analysis of gene regulation at transcript resolution with RNA-seq. Nat Biotechnol. 2013;31(1):46-53.
31. Lohse M, Nagel A, Herter T, May P, Schroda M, Zrenner R, et al. Mercator: a fast and simple web server for genome scale functional annotation of plant sequence data. Plant Cell Environ. 2014;37(5):1250-8.

32. Thimm $O$, Bläsing $O$, Gibon $Y$, Nagel $A$, Meyer $S$, Krüger $P$, et al. MapMan: a user-driven tool to display genomics data sets onto diagrams of metabolic pathways and other biological processes. Plant J. 2004;37(6):914-39.

33. Dash S, Hemert JV, Hong L, Wise RP, Dickerson JA. PLEXdb: gene expression resources for plants and plant pathogens. Nucleic Acids Res. 2012;40(D1): D1194-201.

34. Du Z, Zhou X, Ling Y, Zhang Z, Su Z. agriGO: A GO analysis toolkit for the agricultural community. Nucleic Acids Res 2010; gkq310. https://doi.org/10 1093/nar/gkq310.

35. Fan J, Chen C, Yu Q, Khalaf AA, Achor DS, Brlansky RH, et al. Comparative transcriptional and anatomical analyses of tolerant rough lemon and susceptible sweet orange in response to 'Candidatus Liberibacter asiaticus' infection. Mol Plant-Microbe Interact. 2012;25:1396-07.

36. Livak KJ, Schmittgen TD. Analysis of relative gene expression data using real-time quantitative PCR and the $2^{-\Delta \Delta C T}$ method. Methods. 2001;25(4): $402-8$.

37. Engel LS, Hill JM, Caballero AR, Green LC, O'Callaghan RJ. Protease IV, a unique extracellular protease and virulence factor from Pseudomonas aeruginosa. J Biol Chem. 1998;273:16792-7.

38. Park S-J, Kim S-K, So Y-I, Park H-Y, Li X-H, et al. Protease IV, a quorum sensing-dependent protease of Pseudomonas aeruginosa modulates insect innate immunity. Mol Microbiol. 2014;94:1298-14.

39. Kurz M, Burch AY, Seip B, Lindow SE, Gross H. Genome-driven investigation of compatible solute biosynthesis pathways of Pseudomonas syringae $\mathrm{pv}$. syringae and their contribution to water stress tolerance. Appl Environ Microbiol. 2010;76(16):5452-62.

40. Piazza A, Zimaro T, Garavaglia BS, Ficarra FA, Thomas L, Marondedze C, et al. The dual nature of trehalose in citrus canker disease: a virulence factor for Xanthomonas citri subsp. citri and a trigger for plant defence responses. J Exp Bot. 2015;66(9):2795-11.

41. Tondo ML, Petrocelli S, Ottado J, Orellano EG. The monofunctional catalase KatE of Xanthomonas axonopodis pv. citri is required for full virulence in citrus plants. PLoS One. 2010;5(5):e10803.

42. Etchegaray A, Silva-Stenicoa ME, Moona DH, Tsaia SM. In silico analysis of nonribosomal peptide synthetases of Xanthomonas axonopodis pv. citri: identification of putative siderophore and lipopeptide biosynthetic genes. Microbiol Res. 2004;159:425-37.

43. Wiggerich $\mathrm{H}-\mathrm{G}$, Puhler $\mathrm{A}$. The exbD2 gene as well as the iron-uptake genes tonB, exbB and exbD1 of Xanthomonas campestris pv. campestris are essential for the induction of a hypersensitive response on pepper (Capsicum annuum). Microbiology. 2000;146:1053-60.

44. Andrade MO, Alegria MC, Guzzo CR, Docena C, Rosa MCP, Ramos CHI, Farah CS. The HD-GYP domain of RpfG mediates a direct linkage between the Rpf quorum-sensing pathway and a subset of diguanylate cyclase proteins in the phytopathogen Xanthomonas axonopodis pv citri. Mol Microbiol. 2006; 62(2):537-51.

45. Haines S, Arnaud-Barbe N, Poncet D, Reverchon S, Wawrzyniak J, Nasser W, Renauld-Mongénie $\mathrm{G}$. IscR regulates synthesis of colonization factor antigen I fimbriae in response to iron starvation in enterotoxigenic Escherichia coli. J Bacteriol. 2015;197:2896-07.

46. Merino E, Jensen RA, Yanofsky C. Evolution of bacterial trp operons and their regulation. Curr Opin Microbiol. 2008;11(2):78-86.

47. Schultz D, Wolynes PG, Jacob EB, Onuchic JN. Deciding fate in adverse times: sporulation and competence in Bacillus subtilis. Proc Natl Acad Sci U S A. 2009;106:21027-34.

48. Graham JH, Gottwald TR, Cubero J, Achor DS. Xanthomonas axonopodis pv. citri: factors affecting successful eradication of citrus canker. Mol Plant Pathol. 2004;5:1-15.

49. Gottig N, Garavaglia BS, Daurelio LD, Valentine A, Gehring C, Orellano EG, Ottado J. Xanthomonas axonopodis pv. citri uses a plant natriuretic peptide-like protein to modify host homeostasis. Proc Natl Acad Sci U S A. 2008;105:18631-6.

50. Berger S, Benediktyova Z, Matous K, Bonfig K, Mueller MJ, Roitsch T. Visualization of dynamics of plant-pathogen interaction by novel combination of chlorophyll fluorescence imaging and statistical analysis: differential effects of virulent and avirulent strains of $P$. syringae and of oxylipins on A. thaliana. J Exp Bot. 2007;58:797-06.

51. Iuchi S, Kobayashi M, Taji T, Naramoto M, Seki M, Kato T, et al. Regulation of drought tolerance by gene manip-ulation of 9-cis-epoxycarotenoid 
dioxygenase: a key enzyme in abscisic acid biosynthesis in Arabidopsis. Plant J. 2001;27:325-33.

52. Thomas SG, Phillips AL, Hedden P. Molecular cloning and functional expression of gibberellin 2-oxidases, multifunctional enzymes involved in gibberellin deactivation. Proc Natl Acad Sci U S A. 1999;96:4698-03.

53. Turner JG, Ellis C, Devoto A. The Jasmonate signal pathway. Plant Cell. 2002; 14(Suppl):s153-64.

54. Park SW, Kaimoyo E, Kumar D, Mosher S, Klessig DF. Methyl salicylate is a critical mobile signal for plant systemic acquired resistance. Science. 2007; 318:113-6.

55. Lozano-Duran R, Zipfel C. Trade-off between growth and immunity: role of brassinosteroids. Trends Plant Sci. 2015;20:12-9.

56. Li J, Brader G, Palva ET. Kunitz trypsin inhibitor: An antagonist of cell death triggered by Phytopathogens and Fumonisin B1 in Arabidopsis. Mol Plant. 2008;1(3):482-95.

57. Qi D, Innes RW. Recent advances in plant NLR structure, function, localization and signaling. Front Immunol. 2013. https://doi.org/10.3389/ fimmu.2013.00348.

58. Ambawat S, Sharma P, Yadav NR, Yadav RC. MYB transcription factor genes as regulators for plant responses: an overview. Physiol Mol Biol Plants. 2013; 19(3):307-21.

59. Pandey SP, Somssich IE. The role of WRKY transcription factors in plant immunity. Plant Physiol. 2009;150(4):1648-55.

60. Michael P, Speed M, Fenton A, Jones MG, Ruxton GD, Brockhurst MG. Coevolution can explain defensive secondary metabolite diversity in plants. New Phytol. 2015;208(4):1251-66.

61. Cernadas RA, Camillo LR, Benedetti C. Transcriptional analysis of the sweet orange interaction with the citrus canker pathogens Xanthomonas axonopodis pv. citri and Xanthomonas axonopodis pv. aurantifolii. Mol Plant Pathol. 2008;9(5):609-31.

62. Kraiselburd I, Daurelio LD, Tondo ML, Merelo P, Cortadi AA, Talón M, et al. The LOV protein of Xanthomonas citri subsp. citri plays a significant role in the counteraction of plant immune responses during citrus canker. PLoSONE. 2013:8(11):e80930.

63. Yan $\mathrm{Q}$, Wang N. High-throughput screening and analysis of genes of Xanthomonas citri subsp. citri involved in citrus canker symptom development. Mol Plant-Microbe Interact. 2012;25(1):69-84.

64. Du D, Van VHW MS, Pos KM, Luisi BF. Structure, mechanism and cooperation of bacterial multi drug transporters. Curr. Opin. Struct Biol. 2015:33:76-91.

65. Quistgaard EM, Löw C, Guettou F, Nordlund P. Understanding transport by the major facilitator superfamily (MFS): structures pave the way. Nat Rev Mol Cell Biol. 2016;17:123-32

66. Yu X, Lund SP, Scott RA, Greenwald JW, Records AH, Nettleton D, et al. Transcriptional responses of Pseudomonas syringae to growth in epiphytic versus apoplastic leaf sites. Proc Natl Acad Sci U S A. 2013;1 10:E425-34.

67. Rico A, Preston GM. Pseudomonas syringae pv. tomato DC3000 uses constitutive and apoplast-induced nutrient assimilation pathways to catabolize nutrients that are abundant in the tomato apoplast. Mol PlantMicrobe Interact. 2008;21(2):269-82

68. Chatnaparat T, Prathuangwong S, Lindow SE. Global pattern of gene expression of Xanthomonas axonopodis pv. glycines within soybean leaves. Mole Plant-Microbe Interact. 2016;29(6):508-22.

69. Pandey SS, Patnana PK, Rai R, Chatterjee S. Xanthoferrin, the ahydroxycarboxylate-type siderophore of Xanthomonas campestris pv. campestris, is required for optimum virulence and growth inside cabbage. Mol Plant Pathol. 2017;18(7):949-62

70. Rai R, Javvadi $\mathrm{S}$, Chatterjee $\mathrm{S}$. Cell-cell signalling promotes ferric iron uptake in Xanthomonas oryzae pv. oryzicola that contribute to its virulence and growth inside rice. Mol Microbiol. 2015;96:708-27.

71. Cernadas A, Benedetti CE. Role of auxin and gibberellin in citrus canker development and in the transcriptional control of cell-wall remodeling genes modulated by Xanthomonas axonopodis pv citri. Plant Sci. 2009; 177(3):190-5.

72. French E, Kim B-S, Rivera-Zuluaga K, lyer-Pascuzzi A. Whole root transcriptomic analysis suggests a role for auxin pathways in resistance to Ralstonia solanacearum in tomato. Mol Plant-Microbe Interact. 2018;31(4): 432-44

73. Hann DR, Dominguez-Ferreras A, Motyka V, Dobrev PI, Schornack S, Jehle A, et al. The Pseudomonas type III effector HopQ1 activates cytokinin signaling and interferes with plant innate immunity. New Phytol. 2014;201:585-98.
74. Glazebrook J. Contrasting mechanisms of defense against biotrophic and necrotrophic pathogens. Annu Rev Phytopathol. 2005:43:205-27.

75. De Vleesschauwer D, van Buyten E, Satoh K, Balidion J, Mauleon R, et al. Brassinosteroids antagonize gibberellin- and salicylate-mediated root immunity in rice. Plant Physiol. 2012;158:1833-46.

76. Nahar K, Kyndt T, Hause B, Hofte M, Gheysen G. Brassinosteroids suppress rice defense against root-knot nematodes through antagonism with the jasmonate pathway. Mol Plant-Microbe Interact. 2013;26:106-15.

77. Kazan K, Lyons R. Intervention of phytohormone pathways by pathogen effectors. Plant Cell. 2014;26:2285-09.

78. Ma K-W, Ma W. Phytohormone pathways as targets of pathogens to facilitate infection. Plant Mol Biol. 2016;91:713-25.

79. Monaghan J, Zipfel C. Plant pattern recognition receptor complexes at the plasma membrane. Curr Opin Plant Biol. 2012;15(4):349-57.

80. Trdá L, Boutrot F, Claverie J, Brulé D, Dorey S, Poinssot B. Perception of pathogenic or beneficial bacteria and their evasion of host immunity: pattern recognition receptors in the frontline. Front Plant Sci. 2015;6:219. https://doi.org/10.3389/fpls.2015.00219.

81. Jones JD, Dangl JL. The plant immune system. Nature. 2006;444(7117):323-9.

82. Schulze S, Kay S, Büttner D, Egler M, Eschen-Lippold L, Hause G, et al. Analysis of new type III effectors from Xanthomonas uncovers XopB and XopS as suppressors of plant immunity. New Phytol. 2012;195:894-11.

83. Jha G, Rajeshwari R, Sonti RV. Functional interplay between two Xanthomonas oryzae pv. oryzae secretion systems in modulating virulence on rice. Mol Plant-Microbe Interact. 2007;20(1):31-40.
Ready to submit your research? Choose BMC and benefit from:

- fast, convenient online submission

- thorough peer review by experienced researchers in your field

- rapid publication on acceptance

- support for research data, including large and complex data types

- gold Open Access which fosters wider collaboration and increased citations

- maximum visibility for your research: over 100M website views per year

At BMC, research is always in progress.

Learn more biomedcentral.com/submissions 